\title{
The proteostasis network and its decline in ageing
}

Mark S. Hipp, Prasad Kasturi and F. Ulrich Hart1*

Max Planck Institute of Biochemistry, Department of Cellular Biochemistry

Am Klopferspitz 18, 82152 Martinsried, Germany

*Correspondence to uhartl@ biochem.mpg.de; ORCID: 0000-0002-7941-135X

\section{Author contributions}

The authors contributed equally to all aspects of the article.

\section{Competing interests}

F.U.H. holds stock options in, receives consulting fees from, and is the chair of the scientific advisory board of Proteostasis Therapeutics, Inc. The other authors declare no competing interests. 


\begin{abstract}
Ageing is a major risk factor for the development of many diseases, prominently including neurodegenerative disorders such as Alzheimer and Parkinson disease. A hallmark of many age-related diseases is the dysfunction in protein homeostasis (proteostasis), leading to the accumulation of protein aggregates. In healthy cells, a complex proteostasis network, comprising molecular chaperones as well as proteolytic machineries and their regulators, operates to ensure the maintenance of proteostasis. These factors coordinate protein synthesis with polypeptide folding, the conservation of protein conformation and protein degradation. However, sustaining proteome balance is a challenging task in the face of various external and endogenous stresses that accumulate during ageing. These stresses lead to the decline of proteostasis network capacity and proteome integrity. The resulting accumulation of misfolded and aggregated proteins affects in particular postmitotic cell types such as neurons, manifesting in disease. Recent analyses of proteome-wide changes that occur during ageing inform on strategies to improve proteostasis. The possibilities of pharmacological augmentation of the capacity of proteostasis networks hold great promise for delaying the onset of age-related pathologies associated with proteome deterioration and for extending healthspan.
\end{abstract}




\section{Introduction}

Most proteins must fold into well-defined three-dimensional structures and need to remain folded throughout their life-time in order to perform their biological functions. Moreover, the abundance of each of the thousands of different proteins in a mammalian cell must be carefully controlled. We now appreciate that this state of a balanced proteome, referred to as protein homeostasis (or 'proteostasis' ${ }^{1}$ ), depends on an extensive network of molecular chaperones, proteolytic systems and their regulators, comprising approximately 2000 proteins in human cells ${ }^{2}$. Understanding the organization of this network and its regulation in response to external and endogenous stresses is of fundamental importance in biology and medicine, as the failure to maintain proteostasis is associated with ageing and numerous degenerative diseases ${ }^{3,4}$.

The proteostasis network serves to ensure that correctly folded proteins are generated at the right time and cellular location, and in amounts allowing stoichiometric assembly in case of oligomeric protein complexes. Additionally, it prevents proteins from misfolding and aggregation. Beyond regulation of folding, the proteostasis network also ensures that superfluous and misfolded protein species are removed, either by autophagy or degradation mediated by the proteasome. Together, these mechanisms avoid the accumulation of protein aggregates, which can be potentially toxic (Fig. 1a). Key effectors of the proteostasis network are molecular chaperones, which ensure proper protein folding and conformational maintenance and cooperate with the degradation machinery. Proteostasis is disturbed in various pathologic conditions, prominently including diseases associated with the old age, such as neurodegenerative disorders. This suggests that the capacity of the proteostasis network declines with ageing. 
Recent advances in transcriptome and proteome analysis now make it possible to quantify and measure changes in thousands of different transcripts and proteins. Applying these techniques to the studies of ageing in model organisms, such as the nematode Caenorhabditis elegans, has provided us with new insight into the decline of the proteome during ageing and enables us to identify critical components of the proteostasis network that may be amenable to pharmacological manipulation.

In this Review we discuss our present understanding of the organization of the proteostasis network and its role in health and disease. We describe the age-dependent changes in the soluble and insoluble proteome gathered from studies of model organisms, and we summarize current concepts of aggregate toxicity in neurodegenerative diseases and other pathologies associated with ageing. The prospects of targeting proteostasis networks to reduce the burden of toxic protein aggregates and hamper the development and/or progression of degenerative diseases associated with ageing will also be discussed.

\section{The proteostasis network}

Maintaining a balanced proteome requires cells to coordinate the functions of three interlinked arms of the proteostasis network: protein synthesis and folding, conformational maintenance and degradation (Fig. 1a).

\section{Protein synthesis and folding.}

The proteomes of eukaryotic cells are highly complex, ranging from $\sim 6,000$ different proteins in fungi ${ }^{5}$ to over 10,000 proteins in human cells ${ }^{6}$, with proteome composition varying between cell types and tissues. Recent large-scale sequencing data indicate the presence of a high number of single nucleotide variants in protein coding regions 
in the human population ${ }^{7}$. Mutations can affect protein stability and folding kinetics, possibley resulting in metastable proteins that engage components of the proteostasis network $^{9,10}$. Proteins also vary greatly in abundance, from fewer than 50 copies per cell in case of certain transcription factors up to more than $10^{7}$ molecules for histones, cytoskeletal or ribosomal proteins ${ }^{11,12}$. Protein abundance must be carefully controlled to support cell signalling, the proper flux of substrates through metabolic pathways and to allow the stoichiometric assembly of large macromolecular machines, such as ribosomes or mitochondrial respiratory chain complexes.

The majority of newly-synthesized proteins must fold into defined threedimensional structures in order to attain biological function, with the notable exception of proteins with intrinsically disordered regions that may acquire structure only when interacting with partner molecules ${ }^{13,14}$. Generally, the folded (or native) states of proteins are thermodynamically favorable and all the information necessary for folding is contained within the amino acid sequence of the newly-synthesized polypeptide chain. However, proteins must navigate a complex energy landscape during folding, putting them at risk of adopting kinetically stable (meaning, populating local energy minima) non-native structures (Fig. 1b). These misfolded states also tend to engage in non-productive intermolecular interactions, forming aggregates that may be thermodynamically more stable than the native state. While the folding process was originally thought to occur spontaneously, we now know that many proteins, especially those with more complex structures and/or containing multiple domains, require molecular chaperones to fold efficiently and at a biologically relevant time scale. We define a molecular chaperone as any factor that interacts with and aids in the folding or assembly of another protein without being part of its final structure ${ }^{15}$. Mechanistically, chaperones prevent aggregation and 
promote folding through ATP-dependent and independent mechanisms of protein binding and release (for recent reviews see refs. ${ }^{16-20}$ ). They are classified into different protein families - small heat shock proteins (sHSP), HSP60, HSP70, and HSP90

(Table 1) - and typically recognize exposed hydrophobic amino acid residues and unstructured polypeptide backbones in their substrate proteins, which are unifying features of non-native conformation. In some cases electrostatic interactions between chaperones and clients also have a role ${ }^{21,22}$. Chaperones that participate broadly in the folding of newly-synthesized proteins (de novo folding) act during and after translation to prevent (or reverse) misfolding and aggregation (Fig. 1a and 1b).

Approximately two thirds of proteins must be transported from their site of synthesis in the cytosol to their functional location in a specific subcellular compartment ${ }^{23}$. For proteins destined for the endoplasmic reticulum (ER) and further for the secretory pathway or for the mitochondria, cytosolic chaperones prevent premature folding before the polypeptide reaches its target organelle and shield transmembrane regions from the aqueous cytosol ${ }^{18,24}$. Binding of organellar chaperones at the trans-side of the membrane may then provide the driving force for translocation across the membrane ${ }^{25,26}$. Proteins destined for the nucleus and peroxisomes, and so-called tail-anchored proteins fold before transport.

\section{Maintenance of conformational stability.}

The folded structures of proteins are in most cases only marginally stable. This implies that a substantial proportion of protein species may populate (partially) unfolded states (Fig. 1b), especially in the presence of additional destabilizing factors, such as mutations or external stresses (e.g. elevated temperature, heavy metals or presence of reactive oxygen species). Polypeptides in non-native conformations, i.e. 
nascent chains, folding intermediates and misfolded states, tend to aggregate owing to the exposure of hydrophobic amino acid residues and unpaired $\beta$-strands. Aggregation removes proteins from the pool of functionally active molecules, and thereby leads to a reduction of function of the aggregated protein. Moreover, aggregate species may be cytotoxic in a manner unrelated to their biological role, as will be discussed below.

To avoid the accumulation of misfolded proteins and cytotoxic protein aggregation, the proteostasis network contains molecular chaperones, for many of which transcription is induced under stress conditions through compartment-specific signalling pathways. The main cytosolic response to stress is the heat shock response, which is controlled by a group of transcription factors known as heat shock factors. By binding to heat shock elements in promotor regions these factors control various genes encoding chaperones (heat shock proteins) and other factors of the proteostasis network. The best studied of these is heat-shock transcription factor 1 (HSF1). In nonstressed cells HSF1 is present in an inactive complex with the chaperones HSP90 (ref. ${ }^{27}$ ) and HSP70 (ref. ${ }^{28}$ ). The presence of non-native proteins is thought to result in titration of these chaperones away from HSF1, which then allows HSF1 to trimerize and induce the transcription of heat shock protein-encoding genes ${ }^{29}$. Concomitantly with the induction of members of the proteostasis network, general protein synthesis is attenuated upon stress, which reduces the production of new clients of the proteostasis network. Once the proteotoxic stress has ceased and sufficient free chaperone capacity is reestablished, these factors rebind HSF1 and the system returns to balance ${ }^{30}$. Similar signalling pathways to counter aberrantly folded and/or unfolded proteins are present in the ER and in mitochondria ${ }^{31,32}$.

With few exceptions, homologues of stress-inducible chaperones are also constitutively expressed both in the cytosol and within organelles, including the HSP 
families mentioned above ${ }^{16,18}$. They form cooperative networks to maintain nonnative protein species in solution and mediate their refolding to achieve functional structures (remodelling; Fig. 1a). A distinct set of chaperones function in the conformational maintenance of the secreted proteome in the extracellular space ${ }^{33}$.

\section{Protein degradation.}

In combination with controlled protein synthesis, regulated degradation of proteins is an important mechanism to adjust the levels of functional proteins, thereby regulating important cellular processes such as mitosis ${ }^{34}$ and adapting protein levels in response to environmental changes ${ }^{35,36}$. Protein degradation is also a key mechanism to avoid accumulation of misfolded or faulty protein species, including mutant proteins and unassembled subunits of multiprotein complexes. Proteins are degraded by two major proteolytic pathways, the ubiquitin proteasome system (UPS) and the autophagosomal-lysosomal pathway ${ }^{37-39}$. While degradation by the UPS requires ATP-dependent unfolding of single substrate proteins, the autophagy pathway allows the degradation of protein aggregates and whole organelles. In both proteolytic systems, molecular chaperones cooperate in the recognition of misfolded protein species and help to maintain them in a degradation competent state $\mathrm{e}^{40-42}$.

In targeting aberrant proteins for degradation, the UPS cooperates with the major cytosolic chaperone systems, HSP70 and HSP90, and with chaperone cofactors containing E3 ubiquitin ligase activity, such as the carboxy terminus of HSP70interacting protein (CHIP). CHIP interacts via its tetratricopeptide repeat (TPR) domain with the carboxy-terminus of HSP70 or HSP90 to ubiquitylate foldingincompetent proteins - characterized by a long chaperone residence time ${ }^{43}$ — which targets them to the proteasome. In addition, CHIP has the ability to prevent 
aggregation in the absence of these chaperones ${ }^{44}$. Other components of the UPS, the yeast E3 ligase San1 and the metazoan E2 ubiquitin-conjugating enzyme UBE2O also have inbuilt chaperone properties and bind surplus or misfolded proteins directly ${ }^{45,46}$. UBE2O mediates ubiquitylation without a separate E3 ligase and in reticulocytes mediates the removal of $\alpha$-globin subunits that failed to assemble with $\beta$-globin in the process of haemoglobin assembly ${ }^{46}$. In other proteins, co-translational modifications, such as N-terminal acetylation ${ }^{47}$, function as signals for UPS-mediated degradation when exposed in unassembled subunits. Chaperones also assist in the degradation of misfolded proteins by autophagy ${ }^{48}$. HSC70 (the constitutively expressed member of the HSP70 family) and its co-chaperone BAG3 are involved in the degradation of aggregates in a process known as chaperone-assisted selective autophagy ${ }^{49,50}$. HSC70 also participates in the degradation of soluble cytosolic proteins containing a KFERQ sequence motif by chaperone-mediated autophagy in lysosomes ${ }^{51,52}$ and endosomal microautophagy in late endosomes and multivesicular bodies ${ }^{42,53}$.

\section{Sources of misfolded protein species}

Misfolded protein species originate from multiple sources and pose a constant danger to the cell. Conformational stress conditions, such as heat stress, oxidative stress ${ }^{54}$ or exposure to toxic agents like cadmium ${ }^{55}$ may cause a subset of proteins to unfold, which increases their risk of aggregating. In contrast to proteins with intrinsically disordered regions, some of which inherently possess a high capacity for toxic aggregation, this unfolding step is necessary for the aggregation of globular proteins such as superoxide dismutase 1 , which is associated with amyotrophic lateral sclerosis $(\mathrm{ALS})^{56}$. Moreover, the protein synthesis and folding process is imperfect, despite the presence of abundant chaperone systems, and it has been estimated that 5-30\% of all 
newly-synthesized proteins do not properly fold and need to be targeted for immediate degradation ${ }^{57-59}$. It is well established that folding efficiencies are substantially lower for specific proteins, such as the cystic fibrosis transmembrane conductance regulator (CFTR) and other multi-pass membrane proteins. In the case of CFTR, only $\sim 25 \%$ of synthesized protein matures to the functional chloride channel, with disease-causing mutations reducing folding efficiency even further ${ }^{60,61}$. For some mutations of superoxide dismutase 1 that are associated with familial ALS, it has been shown that initial folding steps are delayed, generating aggregation-prone folding intermediates ${ }^{62}$.

Defective mRNAs are another notable source of aberrant protein products. Translation of mRNAs lacking a stop codon (so-called non-stop mRNAs, arising from truncation or premature cleavage of the transcript and polyadenylation) results in ribosome-stalled polypeptide chains that are folding-incompetent. These chains must be removed by ribosome quality control (RQC) machinery and proteasomal degradation $^{63}$ (see Box 1) to avoid aggregation ${ }^{64-66}$. The importance of the RQC pathway is exemplified by the fact that its failure is associated with age-dependent neurodegeneration in a mouse model $^{67}$. Likewise, tRNA availability may limit translation rates, resulting in protein aggregation, perhaps by increasing the likelihood of misreading or frameshifts, or by increasing the risk that nascent chains occupy nonproductive folding intermediates ${ }^{68}$.

Inefficient import into the target organelles, for example into mitochondria or the ER, will cause cytosolic accumulation of these proteins and constitutes another cause of proteotoxicity ${ }^{69}$. Many secretory proteins require the oxidizing environment of the ER for disulfide bond formation and consequently fail to fold in the reducing 
environment of the cytosol, generating potentially toxic species that need to be eliminated ${ }^{70}$.

\section{Pathology of protein aggregates}

More than 100 years ago, Alois Alzheimer described the appearance of protein "plaques" in the cerebral cortex of a 56 year old patient ${ }^{71}$. Protein aggregate deposits in fibrillar (amyloid -like) form are now widely recognized as a hallmark of many neurodegenerative diseases and other mostly age-dependent pathologies, such as type II diabetes ${ }^{72,73}$. It is generally believed that aggregate formation confers a toxic property to the disease protein ('toxic gain of function'). This contrasts with other diseases associated with protein misfolding, where the defect is often due to mutations that cause loss of function ${ }^{74}$. Cystic fibrosis is one of the most prominent examples of this latter group of diseases ${ }^{75}$.

\section{Formation of pathological aggregates.}

The process of pathological aggregation is characterized by the formation of amyloid fibrils as the end point. Intermediates in this process include soluble oligomeric and protofibrillar states that are structurally less ordered than the fibrils and are thought to contribute strongly to toxicity. Amyloid fibrils are characterized by ordered cross- $\beta$ structure, i.e. parallel or anti-parallel $\beta$-strands running perpendicular to the long fibril axis, and have distinct tinctorial properties ${ }^{76-79}$. Fibrils form via a nucleationdependent polymerization pathway, often associated with a long lag-time ${ }^{80}$. Several possible microscopic processes underlie the characteristic sigmoidal aggregation curves: primary nucleation of monomers in solution or on surfaces, elongation of fibrils through monomer addition to fibril ends, secondary nucleation of oligomers on 
the surface of already existing fibrils and fibril breakage ${ }^{73,81,82}$. Preformed fibrils or fragments thereof may function as seeds for new, accelerated fibril formation. In addition, prion-like cell-to-cell propagation of such seeds is thought to cause the spreading of aggregates in the brains of patients suffering from Alzheimer or Parkinson disease ${ }^{83-86}$.

Notably, amyloid fibrils are not necessarily harmful to cells, as demonstrated by an increasing list of non-disease related amyloids with various cellular functions ${ }^{87}$, including the Curli fibrils of Escherichia coli that mediate the attachment of virulent bacteria to epithelial surfaces ${ }^{88}$ and the mammalian premelanosome protein Pmel17 that provides a template for melanin polymerization ${ }^{89}$. Rather, toxicity arises when various aggregation intermediate states, primarily soluble oligomers (non-fibrillar or proto-fibrillar species), are formed during the process of fibril assembly. In support of this view, 'functional amyloids' appear to have been optimized in evolution so that their formation is associated with a minimal number of aggregation intermediates ${ }^{90,91}$. How this is achieved is a subject of ongoing research. Soluble oligomers are thought to display characteristic structural properties, independent of sequence ${ }^{78,92}$. They are structurally dynamic and expose hydrophobic amino acid residues and unpaired $\beta$ strands to the solvent, features that are largely buried in ordered fibrils. These properties of oligomers confer a high degree of interactivity with cellular proteins and membranes ${ }^{93-96}$. However, amyloid fibrils and amorphous aggregates may also engage in aberrant interactions with proteins and membranes. The exact differences in amount and nature of the interactions of these various aggregate species remain to be established.

A special case of disease-relevant protein aggregation involves liquid-liquid phase separation of certain proteins containing low complexity domains, often with 
prion-like properties ${ }^{97-99}$. In this process a homogeneous solution of molecules spontaneously separates ('demixes') into two coexisting liquid phases — a condensed phase (a non-membrane bound droplet-like compartment) and a depleted phase (the bulk solution). The interface of the condensed droplet forms a boundary that allows the selective passage of some molecules but not others. These phase-separated assemblies provide a general regulatory mechanism to compartmentalize biochemical reactions within cells, enhancing biological reactions or sequestering factors that are temporarily not required ${ }^{99,100}$. Notably, some of these assemblies over time undergo a maturation process, which involves a liquid-to-solid phase transition with the concomitant formation of structures reminiscent of pathological aggregates. These processes can be accelerated by mutations, post-translational modifications, changes in the properties of the solution (salt concentration), metabolic state or in response to increasing molecular concentration ${ }^{98,101,102}$. Thus, phase separation could promote increased rates of nucleation and/or growth of amyloid-like fibres. A prominent example is the aggregation of the predominantly nuclear RNA-binding proteins FUS and TDP-43 in the cytosol, mutations of which are associated with ALS ${ }^{102,103}$. Agerelated changes in the proteome (changes of the balance between synthesis and degradation as well as decline in folding capacity; see also below) and metabolome (changes in the local microenvironment) can lead to aberrant phase transitions that may be a key driver of ageing and disease $\mathrm{e}^{104}$.

\section{Mechanisms of aggregate toxicity.}

How aggregates cause toxicity, cellular dysfunction and eventual death is only partially understood. A large body of evidence points to multiple mechanisms acting in parallel, with specific modes of toxic function being more pronounced in certain 
disease proteins and cell types. Two principal activities at the cellular level can be distinguished: damaging effects on lipid membranes and aberrant interactions with macromolecules, primarily soluble or membrane-associated proteins and RNA molecules (Fig. 2).

Experiments in cell culture and studies with model lipid membranes indicate that soluble oligomers (ranging in size roughly between 20-60 molecules) have the ability to disrupt the integrity of membrane structures in the neuronal synapse and other cellular locations by forming pore-like structures ${ }^{105-107}$ (Fig. 2a). Fibrils, though exposing less hydrophobic surfaces than oligomers, may nevertheless have the capacity to deform or even pierce endomembranes, as shown in vitro $^{79,108}$ and suggested by recent observations of aggregate deposits in situ by cryo-electron tomography ${ }^{109}$ (Fig 2a).

The other well-supported mechanism of proteotoxicity relates to the ability of aggregates to engage in aberrant interactions with multiple cellular proteins (Fig. 2b), such as nucleo-cytoplasmic transport factors, ribonucleoproteins and other proteins with key functions ${ }^{96,110-114}$. The proteins bound by the aggregates tend to be metastable and characteristically contain intrinsically disordered regions or low complexity domains ${ }^{96,111,115-118}$. Based on recent studies, these interactions are primarily initiated by protein oligomers and are first dynamic in nature, but may result in the stable sequestration of target molecules in insoluble aggregate deposits ${ }^{96,114,115}$. Importantly, owing to their ability to recognize and bind misfolded proteins, certain chaperones and other proteostasis components are also prone to be sequestered by aggregates. As a result, chaperones and regulatory chaperone cofactors, such as HSC70 and certain HSP40 regulators of the HSP70 system, are substantially depleted from the soluble, active pool, which negatively impacts the proteostasis network by 
reducing its overall strength and thereby contributes to further aggregate accumulation $^{64,119,120}$. Sequestration of regulatory proteostasis network components also impedes the capacity of cells to induce an effective heat shock response ${ }^{115,121}$. Interestingly, the sustained presence of misfolded proteins may lead to a chronic stress response activation that is ineffective in preventing aggregation. This state has been referred to as a maladaptive stress response and has been shown to impact protein folding and exacerbate disease pathology $y^{122}$.

Expression of aggregation-prone proteins has also been shown to impair protein degradation via autophagy ${ }^{123}$ and the UPS ${ }^{124-127}$. Indeed, some disease aggregates, such as those formed by $C 9$ orf72-encoded glycine-alanine dipeptide repeat proteins associated with $\mathrm{ALS}^{126}$ display a remarkably high association with proteasome complexes, reflecting an (apparently unproductive) attempt of the UPS to degrade aggregate material.

Overall, protein aggregates have the capacity to interfere with the proper function of the proteostasis network. The resulting reduction of available proteostasis network capacity increases protein misfolding, setting in motion a vicious feedforward cycle that may lead to proteostasis collapse ${ }^{128}$ (Fig. 2b).

\section{Means of counteracting proteotoxicity}

The functional proteostasis network antagonizes the build-up of aggregates or strives to neutralize their toxic effects. This may be achieved by fundamentally different strategies. Prevention of aggregation is a primary function of molecular chaperones and is achieved by binding of aggregation-prone folding intermediates, followed by their refolding or degradation. Preexistent aggregates may be shielded by chaperones to block harmful interactions, or be removed by disaggregation or autophagy. 
Alternatively, toxic aggregate species, such as soluble oligomeric species, may be actively converted to large inclusion bodies (containing amorphous or fibrillar aggregates), thereby reducing their reactive surfaces for toxic interactions with cellular components (Fig. 3).

\section{Chaperone mediated prevention of amyloid formation.}

Chaperone systems interfere with amyloid-like aggregation at different kinetic phases of fibril formation. As a result, aggregation may either be completely prevented or the equilibrium between aggregate species changed ${ }^{129}$. Consistent with its central role in the chaperone network, the HSP70-HSP40 system has been shown to inhibit primary nucleation of fibril assembly and fibril elongation of polyglutamine (polyQ) expansion proteins like huntingtin (Htt; mutants of which cause Huntington disease), $\alpha$-synuclein (associated with Parkinson disease) and other neurodegenerative disease proteins ${ }^{130-134}$. HSP40 components have an important role in this process and recruit HSP70 to aggregation-prone proteins ${ }^{134,135}$. The chaperones perform this function by interacting with hydrophobic sequence elements of the aggregating disease proteins. The cylindrical chaperonin TRiC/CCT also acts to inhibit aggregation of various disease proteins $^{129,136,137}$ and has been shown to specifically prevent the formation of toxic oligomers of $\mathrm{Htt}^{129}$. Other chaperones, such as the small BRICHOS domain, may coat the surface of fibrils and inhibit secondary nucleation ${ }^{138}$, thereby interfering with the production of toxic oligomers.

\section{Chaperone-mediated disaggregation.}

Interfering with the production of disease protein halts disease progression and allows for the dissociation of preexisting aggregates, as shown in mouse models of 
Huntington disease ${ }^{139,140}$. Indeed, cells contain specialized chaperone machineries that can dissociate aggregates in an ATP-dependent process. In yeast and other fungi, AAA+ chaperones of the Hsp100 family mediate protein disaggregation in concert with Hsp70 and Hsp40 ${ }^{141,142}$. In metazoans, which lack Hsp100 family members, a network of chaperones including HSP70 and the nucleotide exchange factor HSP110 (an HSP70 homolog) mediates protein disaggregation ${ }^{143,144}$. Notably, disaggregation entails the danger of generating oligomeric, potentially toxic, protein species and therefore must be coupled to the degradation of aggregate material via the UPS or the autophagy-lysosomal pathway. How this timely degradation is achieved remains to be investigated.

\section{Formation of inclusion bodies.}

In conditions of limited proteostasis capacity, cells may reduce aggregate load by actively sequestering smaller aggregates into larger deposits (Fig. 3). Upon heatstress, the chaperone Hsp42, a small HSP (sHSP), mediates the rapid concentration of misfolded proteins into small cytosolic aggregate foci (also referred to as Qbodies $)^{145-148}$, which may give rise to larger inclusions. Interestingly, this "aggregase" function depends on a prion-like, intrinsically disordered sequence of Hsp42 (ref. ${ }^{149}$ ). A related protein, Btn2, fulfills a similar role in the nucleus ${ }^{146}$. Association of sHSP with amorphous aggregate deposits is frequently observed and may shield aggregate surfaces that are available for interactions and facilitate subsequent disaggregation ${ }^{150}$. Inclusion bodies are actively formed in yeast in the vicinity of the vacuole and the nucleus, as well as in the nucleus ${ }^{146,151}$. Mammalian cells concentrate aggregated proteins in so-called "aggresomes" at the microtubule-organizing centre in an ATP and microtubule dependent process ${ }^{152}$. Inclusion bodies may function as a sink to 
lower the level of small diffusible oligomers, and thereby reduce the reactive surface and the amount of bound chaperones, consistent with the reduced capacity of aggregate material in inclusion bodies to engage in aberrant interactions ${ }^{96,114}$. Indeed, the presence of inclusion bodies correlates with improved cell survival in cellular models of neurodegenerative disease ${ }^{153}$. Concentration of aggregates in an inclusion body can also facilitate the asymmetric inheritance of damaged proteins in dividing cells (Fig. 3). This process generates one daughter cell that contains the majority of the aggregated proteins, and a second "rejuvenated" daughter ${ }^{154}$. The lack of cell division in postmitotic cells such as neurons can therefore help to explain why these cells are especially vulnerable to pathologies associated with protein aggregation.

Directing aggregation-prone material to specific organelles has been suggested as yet another strategy to reduce toxicity ${ }^{155,156}$ (Fig. 3). For example, the aggregates of specific disease proteins have been found to be more toxic in the cytosol than the nucleus (and vice versa) and a recent report suggested that upon heat stress, certain misfolded proteins can be detected inside mitochondria, although they lack mitochondrial targeting sequences ${ }^{157}$. The physiological significance and the underlying mechanism of this observation remain unclear, but it is noteworthy that both mitochondria and ER have a higher tolerance for the presence of aggregationprone proteins than the cytosol. This is presumably due to increased capacity of these compartments to maintain aggregation-prone disease proteins in a soluble state due to the presence of compartment-specific chaperone systems ${ }^{158,159}$.

\section{Age-dependent proteostasis decline}

The age-dependent decline in the ability of cells to maintain a functional proteome is regarded as a major driver of age-related cellular dysfunction and degenerative 
diseases $^{2-4,160,161}$. The biological reasons why the proteostasis network deteriorates are complex, but probably relate to a lack of evolutionary pressure for proteome maintenance beyond the point when organisms have produced progeny and passed their genome to the next generation. In model organisms such as C. elegans, a controlled ageing programme is thought to allocate organismal resources to reproduction rather than proteome maintenance ${ }^{162}$ and most genetic manipulations that extend lifespan and improve proteostasis are associated with reduced fecundity (see Box 2).

Recent systemic proteome analyses throughout the lifespan of C. elegans provided insight into age-dependent changes in proteome composition ${ }^{163-167}$. Largescale proteome profiling of about 5,000 different proteins revealed extensive proteome remodelling and the development of severe proteome imbalance during ageing, characterized by extensive changes in the abundance of proteins ${ }^{166}$. About one third of the quantified proteins were found to increase or decrease in abundance by at least 2-fold after day 6 of adulthood. These global changes are thought to be caused (at least in part) by a dysregulation in miRNA-mediated post-transcriptional gene regulation ${ }^{166,168}$. This age-dependent proteome remodelling was substantially less pronounced in long-lived $d a f-2$ mutant worms defective in insulin/insulin-like growth factor signalling (see Box 2), indicative of an improved capacity of the proteostasis network. The extensive proteome remodelling observed during ageing in C. elegans differs from observations in tissues of aged mice, where only minor proteomic changes were detected with a similar experimental approach ${ }^{169}$. Thus, mammals appear to devote greater resources to maintaining proteome balance, limiting agedependent cell-type and organelle-specific proteome changes ${ }^{170}$. 
A hallmark of the ageing proteome is the loss of protein solubility and the accumulation of aggregates. C. elegans has been used extensively as a model to study this process ${ }^{163,164,166}$. A recent quantitation of $\sim 2,100$ aggregating proteins ${ }^{166}$ tested the view that proteins have been optimized in evolution to maintain solubility at their physiological concentrations (prior to age-dependent proteome deregulation), but aggregate when exceeding that concentration ${ }^{171}$ (referred to as critical concentration). The analysis confirmed that proteins of low abundance tend to have higher aggregation propensities during ageing compared to abundant proteins. Nevertheless, highly abundant proteins were found to predominantly contribute to total aggregate load, despite their higher intrinsic solubility ${ }^{166}$. Apparently, the solubility of abundant proteins is insufficient to protect them from age-dependent aggregation since the proteome and proteostasis network changes associated with ageing (see the following paragraph) result in these proteins eventually exceeding the critical concentration, a phenomenon referred to as supersaturation ${ }^{171,172}$.

During ageing the proteostasis network becomes increasingly burdened by increasing loads of misfolded proteins and proteins that have been damaged by oxidative stress $^{173}$, particularly in non-dividing, long-lived cells such as neurons ${ }^{9,174}$. In addition, at least in human brain, the expression of ATP-dependent chaperones is repressed during ageing, which may further promote protein misfolding and aggregation (Fig. 2b) ${ }^{175}$. Once the capacity of the proteostasis network drops below a critical level, aggregation-prone proteins can no longer be maintained in a soluble state. As shown in cellular and organismal models, this threshold is lowered in the presence of additional forms of stress, such as proteasome inhibition ${ }^{176}$ or the presence of mutations that structurally destabilize specific proteins and promote 
misfolding ${ }^{10,177}$. The additional pressure on the proteostasis network causes further protein aggregation in a positive feedback loop ${ }^{125,128}$ (Fig. 2b).

Notably, stem cells are more resistant to age-dependent proteostasis network decline than differentiated cells. It has been demonstrated that human embryonic stem cells exhibit elevated levels of proteasome activity for degrading misfolded proteins ${ }^{178}$. Furthermore, human pluripotent stem cells support the efficient assembly of the TRiC/CCT chaperonin complex, apparently by enhancing the expression of one of its eight subunits, CCT8 (ref. ${ }^{179}$ ), which limits complex assembly when present in substoichiometric amounts. Asymmetric division of stem cells might also have a role in maintaining a balanced proteome, with the differentiating cell inheriting the damaged proteins ${ }^{180-182}$. These mechanisms may contribute to the maintenance of stem cells throughout the animal lifespan. Interestingly, the neural stem cell pool in the brain of adult mice comprises quiescent and activated populations with differences in their proteostasis network. While activated stem cells have active proteasomes, quiescent stem cells were recently shown to rely on large lysosomes for aggregate removal. Lysosomal damage accrued during ageing may reduce the ability of quiescent cells to dispose of aggregates and to activate ${ }^{181}$.

\section{Pro-longevity adaptations}

Studies in model organisms including C. elegans, Drosophila melanogaster and mouse indicate that the ability of the organism to maintain proteostasis correlates strongly with both lifespan and healthspan (i.e. the time during which the organism maintains its functional capacity). Accordingly, adaptations in each arm of the proteostasis network (Fig. 1a), either genetic or through environmental effects, have been shown to prolong lifespan. For example, inhibition of the insulin/insulin-like 
growth factor signalling pathway (daf-2 mutant in C. elegans), the major lifespan extending manipulation in the worm ${ }^{183,184}$, results in a profound upregulation of stress resistance through transcriptional activation of chaperone pathways and increased defence against oxidative stress (Box 2).

\section{Changes in protein synthesis and degradation.}

Protein synthesis is a primary node of proteostasis control and its regulation is critical for cell growth and maintenance of intracellular protein pools. Notably, with increasing age, rates of protein synthesis tend to decline ${ }^{165,185,186}$. As shown in C. elegans, the levels of both cytosolic and mitochondrial ribosomes undergo substantial reduction during ageing (Fig. 4a), especially in the long-lived daf-2 mutant worms ${ }^{166}$. The decline in ribosome abundance may function as an adaptive response to the increased proteotoxic challenges that occur in ageing. Attenuating global translation reduces the production of faulty proteins, thereby easing the burden on molecular chaperones and degradation systems. Indeed, transient inhibition of translation via phosphorylation of translation initiation factor $2 \alpha(\mathrm{eIF} 2 \alpha)$ is an important strategy to protect cells from protein misfolding stress ${ }^{187}$ and is prominently associated with the unfolded protein response of the ER and the integrated stress response ${ }^{31,188}$. Reduction of protein synthesis has beneficial effects, including lifespan extension in worms ${ }^{189-192}$.

An imbalance between the production of misfolded proteins and available proteasome capacity is implicated in various age-related pathologies ${ }^{128,193}$, and a decline in proteasome function has been observed during ageing in model organisms in various tissues and cell types ${ }^{194-196}$. In C. elegans, the abundance of proteasomal subunits was found to increase with age ${ }^{166}(\mathbf{F i g}$. 4a), apparently reflecting an attempt 
of the organism at removing aberrant protein species. Upregulation of proteasomes was further enhanced in the $d a f-2$ mutant.

\section{Adaptations in the chaperone network.}

During human brain ageing, the expression of ATP-dependent chaperones (HSP70 and HSP60) is repressed, which may contribute to the decline of the capacity to counteract protein misfolding ${ }^{175}$. Notably, in C. elegans, the levels of HSP70 and HSP90 chaperones as well as their co-chaperones change only moderately during ageing ${ }^{165,166}$, whereas multiple sHSP increase dramatically ( 15-60-fold), especially in the daf-2 mutant ${ }^{166}$, along with proteins involved in oxidative stress defence that prevent oxidative stress and resulting protein damage ${ }^{166}(\mathbf{F i g}$. 4a). Upregulation of sHSP is also observed in D. melanogaster ${ }^{197}$, as well as in mammalian skeletal muscle ${ }^{198}$ and brain during ageing ${ }^{170}$, suggesting that it is a general phenomenon.

\section{Controlled protein aggregation.}

During ageing in C. elegans several types of sHSP were found to be highly insoluble with a high rate of accumulation in the aggregate fraction ${ }^{166}$ (Fig. 4b). Similar observations have been made in vertebrate systems, including human skeletal muscle as well as in bacteria ${ }^{198-200}$. The recruitment of these chaperones into the insoluble fraction may reflect a controlled attempt of the organism to sequester protein aggregates, consistent with age-dependent formation of aggregates (as inclusion bodies) being a regulated, protective response to lower the pressure on the proteostasis network $^{166}$. The age-dependent increase in sHSP levels may thus reflect a shift in defence strategies from preventing aggregation to selective sequestration of dangerous protein species in aggregate deposits (Fig. 4b). In support of this 
possibility, enhanced aggregation of a subset of proteins with an enrichment of unstructured regions, along with certain sHSP, was observed in long-lived daf-2 mutant worms ${ }^{166}$. Indeed, overexpression of a sHSP (HSP-16) is sufficient to extend the lifespan of C. elegans ${ }^{201}$. This hyper-aggregation under control of insulin/IGF-1 signalling may be a failsafe protective mechanism to reduce the concentration of potentially harmful oligomeric aggregate species, when the first-line defences to prevent aggregation — including prevention of misfolding and remodelling of misfolded proteins - fail ${ }^{202-204}$. These findings are consistent with the view that soluble oligomers are the major proteotoxic species in neurodegenerative diseases and that their sequestration into insoluble aggregates reduces proteotoxicity (Fig. 3).

\section{Conclusions and perspective}

Proteins are essential for most cellular functions. To maintain a functional and balanced proteome cells invest in an extensive machinery comprising molecular chaperones, proteases and other factors. While this sophisticated machinery is sufficient to fulfill its task in young and healthy individuals, its activity declines over time and at some point is no longer able to combat the accumulated effects of proteotoxic insults. As a consequence, ageing is associated with loss of proteome balance and widespread protein aggregation, facilitating the development of degenerative pathologies, such as Alzheimer or Parkinson disease.

As shown first in a mouse model of Huntington disease, the proteostasis network is able to clear aggregates when further synthesis of mutant protein is blocked, allowing the (partial) reversal of disease phenotypes ${ }^{140}$. Accordingly, reducing the expression of aggregation-prone proteins with antisense oligonucleotides

has been shown to be beneficial, even when aggregates have already formed ${ }^{139,205}$. 
Other approaches are the removal of toxic aggregates using specific antibodies and clearance of aggregate-antibody complexes through phagocytosis ${ }^{206,207}$ or the use of small-molecule kinetic stabilizers that bind the native state of disease proteins and prevent their aggregation. A successful example of this latter approach is the small molecule Tafamidis that stabilizes transthyretin tetramers and prevents their dissociation, which is the rate limiting step in transthyretin amyloidogenesis ${ }^{208}$. However, all these approaches are disease specific and in some cases limited to a particular protein mutation. In contrast, augmentation of the proteostasis network has the potential to provide a general means to postpone a range of age-related degenerative conditions or slow their progression ${ }^{209}$. Notably, germ cells and some stem cells have mastered the unlimited propagation and preservation of a healthy proteome. This would suggest that it is possible to carefully augment the proteostasis network and thereby delay the onset or slow the progression of age-dependent degenerative diseases. In principle, this may be achieved by pharmacologically modulating the transcriptional circuits that regulate the different arms of the proteostasis network $^{210}$.

Increasing organismal protein folding capacity is one potential approach to enhance proteostasis capacity. Expression of individual chaperones and cochaperones or pharmacologic activation of stress responses (heat shock response, unfolded protein response) have been demonstrated to ameliorate phenotypes associated with protein aggregation in cellular and organismal models including yeast, C. elegans, D. melanogaster, mammalian cells and the mouse ${ }^{129,130,211-220}$. Furthermore, the exogenous delivery of a recombinant fragment of the chaperonin TRiC/CCT was shown to modulate cellular phenotypes of Huntington disease ${ }^{221}$. Downregulating protein synthesis, thereby reducing the pressure on the chaperone 
machinery, is another strategy to improve proteome quality, mimicking the attenuation of translation associated with activation of unfolded protein response pathways ${ }^{187,222}$.

Enhancing the cellular capacity to dispose of toxic protein species by upregulating proteolytic activity is yet another way to boost the cellular capacity to maintain proteostasis. Small molecule inducers of autophagy, such as rapamycin (and its analogs), show benefits in animal models of different neurodegenerative diseases $^{223}$. Accelerated degradation of proteasomal substrates may result from inhibition of deubiquitylating enzymes ${ }^{224}$ or upregulation of proteasome assembly ${ }^{178,225}$.

Notably however, modulation of the proteostasis network comes at a cost, as it has been pointed out that increasing proteostasis capacity and stress resistance may favour cancer progression ${ }^{226}$. This pro-tumorigenic effect stems from the fact that cancer cell proliferation depends on the function of multiple mutant proteins that require stabilization by the chaperone network ${ }^{227}$. Accordingly, inhibition of chaperones such as HSP90 may be beneficial in the treatment of certain cancers ${ }^{228}$. Overall, as our understanding of the cellular and organismal proteostasis networks improves further, there is justified hope that this knowledge will result in actual benefits to patients with degenerative diseases resulting from protein aggregation and may provide strategies to increase human healthspan. 


\section{Acknowledgments}

We thank David Balchin, Debora Broch-Trentini, Gopal Jayaraj, and Courtney Klaips for critically reading the manuscript. Work in the authors' laboratory is supported by the European Commission under Grant FP7 GA ERC-2012-SyG_318987-ToPAG, and the Deutsche Forschungsgemeinschaft (German Research Foundation) within the framework of the Munich Cluster for Systems Neurology. 


\section{References}

1 Balch, W. E., Morimoto, R. I., Dillin, A. \& Kelly, J. W. Adapting proteostasis for disease intervention. Science 319, 916-919, doi:10.1126/science.1141448 (2008).

First introduction of the term proteostasis and the proteostasis concept.

2 Klaips, C. L., Jayaraj, G. G. \& Hartl, F. U. Pathways of cellular proteostasis in aging and disease. J Cell Biol, doi:10.1083/jcb.201709072 (2017).

3 Taylor, R. C. \& Dillin, A. Aging as an event of proteostasis collapse. Cold Spring Harbor perspectives in biology 3, doi:10.1101/cshperspect.a004440 (2011).

4 Labbadia, J. \& Morimoto, R. I. The biology of proteostasis in aging and disease. Annual review of biochemistry 84, 435-464, doi:10.1146/annurevbiochem-060614-033955 (2015).

5 Picotti, P. et al. A complete mass-spectrometric map of the yeast proteome applied to quantitative trait analysis. Nature 494, 266-270, doi:10.1038/nature11835 (2013).

$6 \quad$ Kulak, N. A., Geyer, P. E. \& Mann, M. Loss-less Nano-fractionator for High Sensitivity, High Coverage Proteomics. Mol Cell Proteomics 16, 694-705, doi:10.1074/mcp.0116.065136 (2017).

$7 \quad$ Lek, M. et al. Analysis of protein-coding genetic variation in 60,706 humans. Nature 536, 285-291, doi:10.1038/nature19057 (2016).

8 Boucher, J. I., Bolon, D. N. \& Tawfik, D. S. Quantifying and understanding the fitness effects of protein mutations: Laboratory versus nature. Protein Sci 25, 1219-1226, doi:10.1002/pro.2928 (2016).

9 Kundra, R., Ciryam, P., Morimoto, R. I., Dobson, C. M. \& Vendruscolo, M. Protein homeostasis of a metastable subproteome associated with Alzheimer's disease. Proc Natl Acad Sci U S A 114, E5703-E5711, doi:10.1073/pnas.1618417114 (2017).

10 Gidalevitz, T., Ben-Zvi, A., Ho, K. H., Brignull, H. R. \& Morimoto, R. I. Progressive disruption of cellular protein folding in models of polyglutamine diseases. Science 311, 1471-1474, doi:10.1126/science.1124514 (2006).

Demonstrates that expression of disease-related mutant proteins disrupts global protein folding.

11 Ghaemmaghami, S. et al. Global analysis of protein expression in yeast. Nature 425, 737-741, doi:10.1038/nature02046 (2003).

12 Geiger, T., Wehner, A., Schaab, C., Cox, J. \& Mann, M. Comparative proteomic analysis of eleven common cell lines reveals ubiquitous but varying expression of most proteins. Mol Cell Proteomics 11, M111 014050, doi:10.1074/mcp.M111.014050 (2012).

13 Demarest, S. J. et al. Mutual synergistic folding in recruitment of CBP/p300 by p160 nuclear receptor coactivators. Nature 415, 549-553, doi:10.1038/415549a (2002).

14 Dunker, A. K., Silman, I., Uversky, V. N. \& Sussman, J. L. Function and structure of inherently disordered proteins. Curr Opin Struct Biol 18, 756-764, doi:10.1016/j.sbi.2008.10.002 (2008).

15 Hartl, F. U. Molecular chaperones in cellular protein folding. Nature 381, 571-579, doi:10.1038/381571a0 (1996). 
16 Kim, Y. E., Hipp, M. S., Bracher, A., Hayer-Hartl, M. \& Hartl, F. U. Molecular chaperone functions in protein folding and proteostasis. Annual review of biochemistry 82, 323-355, doi:10.1146/annurev-biochem-060208-092442 (2013).

17 Hartl, F. U., Bracher, A. \& Hayer-Hartl, M. Molecular chaperones in protein folding and proteostasis. Nature 475, 324-332, doi:10.1038/nature10317 (2011).

18 Balchin, D., Hayer-Hartl, M. \& Hartl, F. U. In vivo aspects of protein folding and quality control. Science 353, aac4354, doi:10.1126/science.aac4354 (2016). 19 Carra, S. et al. The growing world of small heat shock proteins: from structure to functions. Cell Stress Chaperones 22, 601-611, doi:10.1007/s12192017-0787-8 (2017).

20 Lee, C., Kim, H. \& Bardwell, J. C. A. Electrostatic interactions are important for chaperone-client interaction in vivo. Microbiology, doi:10.1099/mic.0.000676 (2018).

21 Joachimiak, L. A., Walzthoeni, T., Liu, C. W., Aebersold, R. \& Frydman, J. The structural basis of substrate recognition by the eukaryotic chaperonin TRiC/CCT. Cell 159, 1042-1055, doi:10.1016/j.cell.2014.10.042 (2014).

22 Koldewey, P., Stull, F., Horowitz, S., Martin, R. \& Bardwell, J. C. A. Forces Driving Chaperone Action. Cell 166, 369-379, doi:10.1016/j.cell.2016.05.054 (2016).

23 Thul, P. J. et al. A subcellular map of the human proteome. Science 356, doi:10.1126/science.aal3321 (2017).

24 Young, J. C., Hoogenraad, N. J. \& Hartl, F. U. Molecular chaperones Hsp90 and Hsp70 deliver preproteins to the mitochondrial import receptor Tom70. Cell 112, 41-50 (2003).

25 Liu, Q., D'Silva, P., Walter, W., Marszalek, J. \& Craig, E. A. Regulated cycling of mitochondrial Hsp70 at the protein import channel. Science 300, 139-141, doi:10.1126/science.1083379 (2003).

26 Schneider, H. C. et al. Mitochondrial Hsp70/MIM44 complex facilitates protein import. Nature 371, 768-774, doi:10.1038/371768a0 (1994).

27 Zou, J., Guo, Y., Guettouche, T., Smith, D. F. \& Voellmy, R. Repression of heat shock transcription factor HSF1 activation by HSP90 (HSP90 complex) that forms a stress-sensitive complex with HSF1. Cell 94, 471-480 (1998).

28 Zheng, X. et al. Dynamic control of Hsf1 during heat shock by a chaperone switch and phosphorylation. Elife 5, doi:10.7554/eLife.18638 (2016).

29 Anckar, J. \& Sistonen, L. Regulation of HSF1 function in the heat stress response: implications in aging and disease. Annual review of biochemistry $\mathbf{8 0}$, 1089-1115, doi:10.1146/annurev-biochem-060809-095203 (2011).

30 Gomez-Pastor, R., Burchfiel, E. T. \& Thiele, D. J. Regulation of heat shock transcription factors and their roles in physiology and disease. Nat Rev Mol Cell Biol 19, 4-19, doi:10.1038/nrm.2017.73 (2018).

31 Walter, P. \& Ron, D. The unfolded protein response: from stress pathway to homeostatic regulation. Science 334, 1081-1086,

doi:10.1126/science.1209038 (2011).

32 Shpilka, T. \& Haynes, C. M. The mitochondrial UPR: mechanisms, physiological functions and implications in ageing. Nat Rev Mol Cell Biol 19, 109120, doi:10.1038/nrm.2017.110 (2018). 
33 Wyatt, A. R., Yerbury, J. J., Ecroyd, H. \& Wilson, M. R. Extracellular chaperones and proteostasis. Annual review of biochemistry 82, 295-322, doi:10.1146/annurev-biochem-072711-163904 (2013).

34 Glotzer, M., Murray, A. W. \& Kirschner, M. W. Cyclin is degraded by the ubiquitin pathway. Nature 349, 132-138, doi:10.1038/349132a0 (1991).

35 Faust, J. R., Luskey, K. L., Chin, D. J., Goldstein, J. L. \& Brown, M. S. Regulation of synthesis and degradation of 3-hydroxy-3-methylglutarylcoenzyme A reductase by low density lipoprotein and 25-hydroxycholesterol in UT-1 cells. Proc Natl Acad Sci U S A 79, 5205-5209 (1982).

36 Murakami, Y. et al. Ornithine decarboxylase is degraded by the $26 \mathrm{~S}$ proteasome without ubiquitination. Nature 360, 597-599, doi:10.1038/360597a0 (1992).

37 Ciechanover, A. Intracellular protein degradation: From a vague idea thru the lysosome and the ubiquitin-proteasome system and onto human diseases and drug targeting. Best Pract Res Clin Haematol 30, 341-355, doi:10.1016/j.beha.2017.09.001 (2017).

38 Dikic, I. Proteasomal and Autophagic Degradation Systems. Annual review of biochemistry 86, 193-224, doi:10.1146/annurev-biochem-061516-044908 (2017).

39 Varshavsky, A. The ubiquitin system, an immense realm. Annual review of biochemistry 81, 167-176, doi:10.1146/annurev-biochem-051910-094049

(2012).

40 Arndt, V., Rogon, C. \& Höhfeld, J. To be, or not to be--molecular chaperones in protein degradation. Cellular and molecular life sciences : CMLS 64, 2525-2541, doi:10.1007/s00018-007-7188-6 (2007).

41 Shiber, A. \& Ravid, T. Chaperoning proteins for destruction: diverse roles of Hsp70 chaperones and their co-chaperones in targeting misfolded proteins to the proteasome. Biomolecules 4, 704-724, doi:10.3390/biom4030704 (2014).

42 Tekirdag, K. \& Cuervo, A. M. Chaperone-mediated autophagy and endosomal microautophagy: Joint by a chaperone. J Biol Chem 293, 5414-5424, doi:10.1074/jbc.R117.818237 (2018).

43 Esser, C., Alberti, S. \& Hohfeld, J. Cooperation of molecular chaperones with the ubiquitin/proteasome system. Biochim Biophys Acta 1695, 171-188, doi:10.1016/j.bbamcr.2004.09.020 (2004).

44 Rosser, M. F., Washburn, E., Muchowski, P. J., Patterson, C. \& Cyr, D. M. Chaperone functions of the E3 ubiquitin ligase CHIP. J Biol Chem 282, 2226722277, doi:10.1074/jbc.M700513200 (2007).

45 Rosenbaum, J. C. et al. Disorder targets misorder in nuclear quality control degradation: a disordered ubiquitin ligase directly recognizes its misfolded substrates. Mol Cell 41, 93-106, doi:10.1016/j.molcel.2010.12.004 (2011). 46 Yanagitani, K., Juszkiewicz, S. \& Hegde, R. S. UBE20 is a quality control factor for orphans of multiprotein complexes. Science 357, 472-475, doi:10.1126/science.aan0178 (2017).

47 Hwang, C. S., Shemorry, A. \& Varshavsky, A. N-terminal acetylation of cellular proteins creates specific degradation signals. Science 327, 973-977, doi:10.1126/science.1183147 (2010).

Introduces $\mathrm{N}$-terminal acetylation as a signal for proteasomal degradation to regulate the removal of non-assembled protein subunits of oligomeric complexes. 
48 Kettern, N., Dreiseidler, M., Tawo, R. \& Hohfeld, J. Chaperone-assisted degradation: multiple paths to destruction. Biol Chem 391, 481-489,

doi:10.1515/BC.2010.058 (2010).

49 Arndt, V. et al. Chaperone-assisted selective autophagy is essential for muscle maintenance. Current biology : CB 20, 143-148, doi:10.1016/j.cub.2009.11.022 (2010).

50 Gamerdinger, M., Kaya, A. M., Wolfrum, U., Clement, A. M. \& Behl, C. BAG3 mediates chaperone-based aggresome-targeting and selective autophagy of misfolded proteins. EMBO Rep 12, 149-156, doi:10.1038/embor.2010.203 (2011).

51 Chiang, H. L., Terlecky, S. R., Plant, C. P. \& Dice, J. F. A role for a 70 kilodalton heat shock protein in lysosomal degradation of intracellular proteins. Science 246, 382-385 (1989).

52 Kaushik, S. \& Cuervo, A. M. The coming of age of chaperone-mediated autophagy. Nat Rev Mol Cell Biol 19, 365-381, doi:10.1038/s41580-018-0001-6 (2018).

53 Sahu, R. et al. Microautophagy of cytosolic proteins by late endosomes. Dev Cell 20, 131-139, doi:10.1016/j.devcel.2010.12.003 (2011).

54 Sies, H., Berndt, C. \& Jones, D. P. Oxidative Stress. Annual review of biochemistry 86, 715-748, doi:10.1146/annurev-biochem-061516-045037 (2017).

55 Jacobson, T. et al. Cadmium Causes Misfolding and Aggregation of Cytosolic Proteins in Yeast. Mol Cell Biol 37, doi:10.1128/MCB.00490-16 (2017). 56 Lang, L., Kurnik, M., Danielsson, J. \& Oliveberg, M. Fibrillation precursor of superoxide dismutase 1 revealed by gradual tuning of the protein-folding equilibrium. Proc Natl Acad Sci U S A 109, 17868-17873, doi:10.1073/pnas.1201795109 (2012).

57 Schubert, U. et al. Rapid degradation of a large fraction of newly synthesized proteins by proteasomes. Nature 404, 770-774, doi:10.1038/35008096 (2000).

58 Vabulas, R. M. \& Hartl, F. U. Protein synthesis upon acute nutrient restriction relies on proteasome function. Science 310, 1960-1963, doi:10.1126/science.1121925 (2005).

59 Duttler, S., Pechmann, S. \& Frydman, J. Principles of cotranslational ubiquitination and quality control at the ribosome. Mol Cell 50, 379-393, doi:10.1016/j.molcel.2013.03.010 (2013).

60 Ward, C. L. \& Kopito, R. R. Intracellular turnover of cystic fibrosis transmembrane conductance regulator. Inefficient processing and rapid degradation of wild-type and mutant proteins. J Biol Chem 269, 25710-25718 (1994).

61 Lukacs, G. L. et al. Conformational maturation of CFTR but not its mutant counterpart (delta F508) occurs in the endoplasmic reticulum and requires ATP. The EMBO journal 13, 6076-6086 (1994).

62 Bruns, C. K. \& Kopito, R. R. Impaired post-translational folding of familial ALS-linked $\mathrm{Cu}$, Zn superoxide dismutase mutants. The EMBO journal 26, 855866, doi:10.1038/sj.emboj.7601528 (2007).

63 Brandman, O. \& Hegde, R. S. Ribosome-associated protein quality control. Nature structural \& molecular biology 23, 7-15, doi:10.1038/nsmb.3147 (2016). 
64 Choe, Y. J. et al. Failure of RQC machinery causes protein aggregation and proteotoxic stress. Nature 531, 191-195, doi:10.1038/nature16973 (2016). 65 Yonashiro, R. et al. The Rqc2/Tae2 subunit of the ribosome-associated quality control (RQC) complex marks ribosome-stalled nascent polypeptide chains for aggregation. Elife 5, e11794, doi:10.7554/eLife.11794 (2016).

66 Defenouillere, Q. et al. Cdc48-associated complex bound to 60S particles is required for the clearance of aberrant translation products. Proc Natl Acad Sci U $S$ A 110, 5046-5051, doi:10.1073/pnas.1221724110 (2013).

67 Chu, J. et al. A mouse forward genetics screen identifies LISTERIN as an E3 ubiquitin ligase involved in neurodegeneration. Proc Natl Acad Sci U S A 106, 2097-2103, doi:10.1073/pnas.0812819106 (2009).

68 Nedialkova, D. D. \& Leidel, S. A. Optimization of Codon Translation Rates via tRNA Modifications Maintains Proteome Integrity. Cell 161, 1606-1618, doi:10.1016/j.cell.2015.05.022 (2015).

\section{Shows that codon-specific translational pausing can cause protein misfolding.}

69 Wrobel, L. et al. Mistargeted mitochondrial proteins activate a proteostatic response in the cytosol. Nature 524, 485-488, doi:10.1038/nature14951 (2015).

70 Park, S. H. et al. The cytoplasmic Hsp70 chaperone machinery subjects misfolded and endoplasmic reticulum import-incompetent proteins to degradation via the ubiquitin-proteasome system. Mol Biol Cell 18, 153-165, doi:10.1091/mbc.e06-04-0338 (2007).

71 Alzheimer, A. Uber eigenartige Krankheitsfalle des spateren Alters: (On certain peculiar diseases of old age. History of Psychiatry 2, 74-101, doi:10.1177/0957154X9100200506 (1991).

72 Mukherjee, A., Morales-Scheihing, D., Butler, P. C. \& Soto, C. Type 2 diabetes as a protein misfolding disease. Trends Mol Med 21, 439-449, doi:10.1016/j.molmed.2015.04.005 (2015).

73 Iadanza, M. G., Jackson, M. P., Hewitt, E. W., Ranson, N. A. \& Radford, S. E. A new era for understanding amyloid structures and disease. Nat Rev Mol Cell Biol, doi:10.1038/s41580-018-0060-8 (2018).

74 Winklhofer, K. F., Tatzelt, J. \& Haass, C. The two faces of protein misfolding: gain- and loss-of-function in neurodegenerative diseases. The EMBO journal 27, 336-349, doi:10.1038/sj.emboj.7601930 (2008).

75 Lukacs, G. L. \& Verkman, A. S. CFTR: folding, misfolding and correcting the DeltaF508 conformational defect. Trends Mol Med 18, 81-91, doi:10.1016/j.molmed.2011.10.003 (2012).

76 Riek, R. \& Eisenberg, D. S. The activities of amyloids from a structural perspective. Nature 539, 227-235, doi:10.1038/nature20416 (2016).

77 Landreh, M. et al. The formation, function and regulation of amyloids: insights from structural biology. J Intern Med 280, 164-176, doi:10.1111/joim.12500 (2016).

78 Chiti, F. \& Dobson, C. M. Protein Misfolding, Amyloid Formation, and Human Disease: A Summary of Progress Over the Last Decade. Annual review of biochemistry 86, 27-68, doi:10.1146/annurev-biochem-061516-045115 (2017). 79 Tipping, K. W., van Oosten-Hawle, P., Hewitt, E. W. \& Radford, S. E. Amyloid Fibres: Inert End-Stage Aggregates or Key Players in Disease? Trends in biochemical sciences 40, 719-727, doi:10.1016/j.tibs.2015.10.002 (2015). 
80 Arosio, P., Knowles, T. P. \& Linse, S. On the lag phase in amyloid fibril formation. Phys Chem Chem Phys 17, 7606-7618, doi:10.1039/c4cp05563b (2015).

81 Arosio, P., Vendruscolo, M., Dobson, C. M. \& Knowles, T. P. Chemical kinetics for drug discovery to combat protein aggregation diseases. Trends Pharmacol Sci 35, 127-135, doi:10.1016/j.tips.2013.12.005 (2014).

82 Wagner, A. S. et al. Self-assembly of Mutant Huntingtin Exon-1 Fragments into Large Complex Fibrillar Structures Involves Nucleated Branching. J Mol Biol 430, 1725-1744, doi:10.1016/j.jmb.2018.03.017 (2018).

83 Brundin, P., Melki, R. \& Kopito, R. Prion-like transmission of protein aggregates in neurodegenerative diseases. Nature reviews. Molecular cell biology 11, 301-307, doi:10.1038/nrm2873 (2010).

$84 \mathrm{Li}$, J. Y. et al. Lewy bodies in grafted neurons in subjects with Parkinson's disease suggest host-to-graft disease propagation. Nature medicine 14, 501-503, doi:10.1038/nm1746 (2008).

85 Sibilla, C. \& Bertolotti, A. Prion Properties of SOD1 in Amyotrophic Lateral Sclerosis and Potential Therapy. Cold Spring Harbor perspectives in biology $\mathbf{9}$, doi:10.1101/cshperspect.a024141 (2017).

86 Guo, J. L. et al. Unique pathological tau conformers from Alzheimer's brains transmit tau pathology in nontransgenic mice. J Exp Med 213, 2635-2654, doi:10.1084/jem.20160833 (2016).

87 Chiti, F. \& Dobson, C. M. Protein misfolding, functional amyloid, and human disease. Annual review of biochemistry 75, 333-366, doi:10.1146/annurev.biochem.75.101304.123901 (2006).

88 Chapman, M. R. et al. Role of Escherichia coli curli operons in directing amyloid fiber formation. Science 295, 851-855, doi:10.1126/science.1067484 (2002).

89 Fowler, D. M. et al. Functional amyloid formation within mammalian tissue. PLoS biology 4, e6, doi:10.1371/journal.pbio.0040006 (2006).

90 Sengupta, U., Nilson, A. N. \& Kayed, R. The Role of Amyloid-beta Oligomers in Toxicity, Propagation, and Immunotherapy. EBioMedicine 6, 42-49, doi:10.1016/j.ebiom.2016.03.035 (2016).

91 Jackson, M. P. \& Hewitt, E. W. Why are Functional Amyloids Non-Toxic in Humans? Biomolecules 7, doi:10.3390/biom7040071 (2017).

92 Kayed, R. et al. Common structure of soluble amyloid oligomers implies common mechanism of pathogenesis. Science 300, 486-489, doi:10.1126/science.1079469 (2003).

93 Miller, J. et al. Identifying polyglutamine protein species in situ that best predict neurodegeneration. Nat Chem Biol 7, 925-934,

doi:10.1038/nchembio.694 (2011).

94 Cheon, M. et al. Structural reorganisation and potential toxicity of oligomeric species formed during the assembly of amyloid fibrils. PLoS Comput Biol 3, 1727-1738, doi:10.1371/journal.pcbi.0030173 (2007).

95 Sangwan, S. et al. Atomic structure of a toxic, oligomeric segment of SOD1 linked to amyotrophic lateral sclerosis (ALS). Proc Natl Acad Sci U S A 114, 87708775, doi:10.1073/pnas.1705091114 (2017).

96 Kim, Y. E. et al. Soluble Oligomers of PolyQ-Expanded Huntingtin Target a Multiplicity of Key Cellular Factors. Mol Cell, doi:10.1016/j.molcel.2016.07.022 (2016). 
97 Franzmann, T. M. et al. Phase separation of a yeast prion protein promotes cellular fitness. Science 359, doi:10.1126/science.aao5654 (2018).

98 Mateju, D. et al. An aberrant phase transition of stress granules triggered by misfolded protein and prevented by chaperone function. The EMBO journal 36, 1669-1687, doi:10.15252/embj.201695957 (2017).

99 Shin, Y. \& Brangwynne, C. P. Liquid phase condensation in cell physiology and disease. Science 357, doi:10.1126/science.aaf4382 (2017).

100 Banani, S. F., Lee, H. O., Hyman, A. A. \& Rosen, M. K. Biomolecular condensates: organizers of cellular biochemistry. Nat Rev Mol Cell Biol 18, 285298, doi:10.1038/nrm.2017.7 (2017).

101 Molliex, A. et al. Phase separation by low complexity domains promotes stress granule assembly and drives pathological fibrillization. Cell 163, 123-133, doi:10.1016/j.cell.2015.09.015 (2015).

102 Patel, A. et al. A Liquid-to-Solid Phase Transition of the ALS Protein FUS Accelerated by Disease Mutation. Cell 162, 1066-1077, doi:10.1016/j.cell.2015.07.047 (2015).

103 Gopal, P. P., Nirschl, J. J., Klinman, E. \& Holzbaur, E. L. Amyotrophic lateral sclerosis-linked mutations increase the viscosity of liquid-like TDP-43 RNP granules in neurons. Proc Natl Acad Sci U S A 114, E2466-E2475, doi:10.1073/pnas.1614462114 (2017).

104 Alberti, S. \& Hyman, A. A. Are aberrant phase transitions a driver of cellular aging? Bioessays 38, 959-968, doi:10.1002/bies.201600042 (2016). 105 Lashuel, H. A., Hartley, D., Petre, B. M., Walz, T. \& Lansbury, P. T., Jr. Neurodegenerative disease: amyloid pores from pathogenic mutations. Nature 418, 291, doi:10.1038/418291a (2002).

Demonstration that mutant amyloidogenic proteins can form pores in membranes.

106 Anguiano, M., Nowak, R. J. \& Lansbury, P. T., Jr. Protofibrillar islet amyloid polypeptide permeabilizes synthetic vesicles by a pore-like mechanism that may be relevant to type II diabetes. Biochemistry 41, 11338-11343 (2002).

107 Lashuel, H. A. \& Lansbury, P. T., Jr. Are amyloid diseases caused by protein aggregates that mimic bacterial pore-forming toxins? Q Rev Biophys 39, 167-201, doi:10.1017/S0033583506004422 (2006).

108 Milanesi, L. et al. Direct three-dimensional visualization of membrane disruption by amyloid fibrils. Proc Natl Acad Sci U S A 109, 20455-20460, doi:10.1073/pnas.1206325109 (2012).

Demonstrates using cryo-electron tomography that fibrils can damage membranes.

109 Bauerlein, F. J. B. et al. In Situ Architecture and Cellular Interactions of PolyQ Inclusions. Cell 171, 179-187 e110, doi:10.1016/j.cell.2017.08.009 (2017). 110 Chou, C. C. et al. TDP-43 pathology disrupts nuclear pore complexes and nucleocytoplasmic transport in ALS/FTD. Nat Neurosci, doi:10.1038/s41593017-0047-3 (2018).

111 Woerner, A. C. et al. Cytoplasmic protein aggregates interfere with nucleocytoplasmic transport of protein and RNA. Science 351, 173-176, doi:10.1126/science.aad2033 (2016).

112 Zhang, Y. J. et al. C9ORF72 poly(GA) aggregates sequester and impair HR23 and nucleocytoplasmic transport proteins. Nat Neurosci 19, 668-677, doi:10.1038/nn.4272 (2016). 
113 Gasset-Rosa, F. et al. Polyglutamine-Expanded Huntingtin Exacerbates Age-Related Disruption of Nuclear Integrity and Nucleocytoplasmic Transport. Neuron 94, 48-57 e44, doi:10.1016/j.neuron.2017.03.027 (2017).

114 Ramdzan, Y. M. et al. Huntingtin Inclusions Trigger Cellular Quiescence, Deactivate Apoptosis, and Lead to Delayed Necrosis. Cell Rep 19, 919-927, doi:10.1016/j.celrep.2017.04.029 (2017).

115 Olzscha, H. et al. Amyloid-like aggregates sequester numerous metastable proteins with essential cellular functions. Cell 144, 67-78, doi:10.1016/j.cell.2010.11.050 (2011).

Describes soluble protein sequestration in aggregates as a basic mechanism of aggregate toxicity.

116 Lin, Y. et al. Toxic PR Poly-Dipeptides Encoded by the C9orf72 Repeat Expansion Target LC Domain Polymers. Cell 167, 789-802 e712, doi:10.1016/j.cell.2016.10.003 (2016).

117 Lee, K. H. et al. C9orf72 Dipeptide Repeats Impair the Assembly, Dynamics, and Function of Membrane-Less Organelles. Cell 167, 774-788 e717, doi:10.1016/j.cell.2016.10.002 (2016).

118 Hosp, F. et al. Spatiotemporal Proteomic Profiling of Huntington's Disease Inclusions Reveals Widespread Loss of Protein Function. Cell Rep 21, 2291-2303, doi:10.1016/j.celrep.2017.10.097 (2017).

119 Park, S. H. et al. PolyQ Proteins Interfere with Nuclear Degradation of Cytosolic Proteins by Sequestering the Sis1p Chaperone. Cell 154, 134-145, doi:10.1016/j.cell.2013.06.003 (2013).

$120 \mathrm{Yu}$, A. et al. Protein aggregation can inhibit clathrin-mediated endocytosis by chaperone competition. Proc Natl Acad Sci U S A 111, E1481-1490, doi:10.1073/pnas.1321811111 (2014).

121 Chafekar, S. M. \& Duennwald, M. L. Impaired heat shock response in cells expressing full-length polyglutamine-expanded huntingtin. PloS one 7, e37929, doi:10.1371/journal.pone.0037929 (2012).

122 Roth, D. M. et al. Modulation of the maladaptive stress response to manage diseases of protein folding. PLoS biology 12, e1001998, doi:10.1371/journal.pbio.1001998 (2014).

123 Ashkenazi, A. et al. Polyglutamine tracts regulate beclin 1-dependent autophagy. Nature 545, 108-111, doi:10.1038/nature22078 (2017).

124 Bence, N. F., Sampat, R. M. \& Kopito, R. R. Impairment of the ubiquitinproteasome system by protein aggregation. Science 292, 1552-1555, doi:10.1126/science.292.5521.1552 (2001).

Shows that expression of aggregation-prone proteins interferes with the function of the ubiquitin proteasome system.

125 Hipp, M. S. et al. Indirect inhibition of $26 \mathrm{~S}$ proteasome activity in a cellular model of Huntington's disease. J Cell Biol 196, 573-587,

doi:10.1083/jcb.201110093 (2012).

126 Guo, Q. et al. In Situ Structure of Neuronal C9orf72 Poly-GA Aggregates Reveals Proteasome Recruitment. Cell 172, 696-705 e612, doi:10.1016/j.cell.2017.12.030 (2018).

Uses cryo-electron tomography to show that proteasomes are sequestered inside aggregates. 
127 Deriziotis, P. et al. Misfolded PrP impairs the UPS by interaction with the 20 S proteasome and inhibition of substrate entry. The EMBO journal 30, 30653077, doi:10.1038/emboj.2011.224 (2011).

128 Hipp, M. S., Park, S. H. \& Hartl, F. U. Proteostasis impairment in proteinmisfolding and -aggregation diseases. Trends in cell biology 24, 506-514, doi:10.1016/j.tcb.2014.05.003 (2014).

129 Behrends, C. et al. Chaperonin TRiC promotes the assembly of polyQ expansion proteins into nontoxic oligomers. Mol Cell 23, 887-897, doi:10.1016/j.molcel.2006.08.017 (2006).

130 Muchowski, P. J. et al. Hsp70 and hsp40 chaperones can inhibit selfassembly of polyglutamine proteins into amyloid-like fibrils. P Natl Acad Sci USA 97, 7841-7846, doi:10.1073/pnas.140202897 (2000).

131 Schaffar, G. et al. Cellular toxicity of polyglutamine expansion proteins: mechanism of transcription factor deactivation. Mol Cell 15, 95-105, doi:10.1016/j.molcel.2004.06.029 (2004).

132 Dedmon, M. M., Christodoulou, J., Wilson, M. R. \& Dobson, C. M. Heat shock protein 70 inhibits alpha-synuclein fibril formation via preferential binding to prefibrillar species. J Biol Chem 280, 14733-14740, doi:10.1074/jbc.M413024200 (2005).

133 Rujano, M. A., Kampinga, H. H. \& Salomons, F. A. Modulation of polyglutamine inclusion formation by the Hsp70 chaperone machine. Exp Cell Res 313, 3568-3578, doi:10.1016/j.yexcr.2007.07.034 (2007).

134 Kakkar, V., Kuiper, E. F., Pandey, A., Braakman, I. \& Kampinga, H. H. Versatile members of the DNAJ family show Hsp70 dependent anti-aggregation activity on RING1 mutant parkin C289G. Sci Rep 6, 34830, doi:10.1038/srep34830 (2016).

135 Lotz, G. P. et al. Hsp70 and Hsp40 functionally interact with soluble mutant huntingtin oligomers in a classic ATP-dependent reaction cycle. J Biol Chem 285, 38183-38193, doi:10.1074/jbc.M110.160218 (2010).

136 Tam, S., Geller, R., Spiess, C. \& Frydman, J. The chaperonin TRiC controls polyglutamine aggregation and toxicity through subunit-specific interactions. Nat Cell Biol 8, 1155-1162, doi:10.1038/ncb1477 (2006).

137 Kitamura, A. et al. Cytosolic chaperonin prevents polyglutamine toxicity with altering the aggregation state. Nat Cell Biol 8, 1163-1170, doi:10.1038/ncb1478 (2006).

138 Cohen, S. I. A. et al. A molecular chaperone breaks the catalytic cycle that generates toxic Abeta oligomers. Nature structural \& molecular biology 22, 207213, doi:10.1038/nsmb.2971 (2015).

139 Kordasiewicz, H. B. et al. Sustained therapeutic reversal of Huntington's disease by transient repression of huntingtin synthesis. Neuron 74, 1031-1044, doi:10.1016/j.neuron.2012.05.009 (2012).

140 Yamamoto, A., Lucas, J. J. \& Hen, R. Reversal of neuropathology and motor dysfunction in a conditional model of Huntington's disease. Cell 101, 57-66, doi:10.1016/S0092-8674(00)80623-6 (2000).

Demonstrates that disease-related aggregates can be cleared when synthesis of the disease protein is blocked.

141 Glover, J. R. \& Lindquist, S. Hsp104, Hsp70, and Hsp40: a novel chaperone system that rescues previously aggregated proteins. Cell 94, 73-82, doi:S00928674(00)81223-4 [pii] (1998). 
142 Parsell, D. A., Kowal, A. S., Singer, M. A. \& Lindquist, S. Protein disaggregation mediated by heat-shock protein Hsp104. Nature 372, 475-478, doi:10.1038/372475a0 (1994).

143 Nillegoda, N. B. et al. Crucial HSP70 co-chaperone complex unlocks metazoan protein disaggregation. Nature 524, 247-251, doi:10.1038/nature14884 (2015).

Describes a metazoan chaperone system for protein disaggregation. 144 Mogk, A., Bukau, B. \& Kampinga, H. H. Cellular Handling of Protein Aggregates by Disaggregation Machines. Mol Cell 69, 214-226, doi:10.1016/j.molcel.2018.01.004 (2018).

145 Escusa-Toret, S., Vonk, W. I. \& Frydman, J. Spatial sequestration of misfolded proteins by a dynamic chaperone pathway enhances cellular fitness during stress. Nat Cell Biol 15, 1231-1243, doi:10.1038/ncb2838 (2013).

Defines aggregation of misfolded proteins as a process important in maintaining proteostasis during stress.

146 Miller, S. B. et al. Compartment-specific aggregases direct distinct nuclear and cytoplasmic aggregate deposition. The EMBO journal 34, 778-797, doi:10.15252/embj.201489524 (2015).

147 Wallace, E. W. et al. Reversible, Specific, Active Aggregates of Endogenous Proteins Assemble upon Heat Stress. Cell 162, 1286-1298, doi:10.1016/j.cell.2015.08.041 (2015).

148 Malinovska, L., Kroschwald, S., Munder, M. C., Richter, D. \& Alberti, S. Molecular chaperones and stress-inducible protein-sorting factors coordinate the spatiotemporal distribution of protein aggregates. Mol Biol Cell 23, 30413056, doi:10.1091/mbc.E12-03-0194 (2012).

149 Grousl, T. et al. A prion-like domain in Hsp42 drives chaperone-facilitated aggregation of misfolded proteins. J Cell Biol 217, 1269-1285, doi:10.1083/jcb.201708116 (2018).

150 Mogk, A. \& Bukau, B. Role of sHsps in organizing cytosolic protein aggregation and disaggregation. Cell Stress Chaperones 22, 493-502, doi:10.1007/s12192-017-0762-4 (2017).

151 Kaganovich, D., Kopito, R. \& Frydman, J. Misfolded proteins partition between two distinct quality control compartments. Nature 454, 1088-1095, doi:10.1038/nature07195 (2008).

Introduces the concept of spatial control of aggregate deposition in distinct cellular locations.

152 Kopito, R. R. Aggresomes, inclusion bodies and protein aggregation. Trends in cell biology 10, 524-530 (2000).

153 Arrasate, M., Mitra, S., Schweitzer, E., Segal, M. \& Finkbeiner, S. Inclusion body formation reduces levels of mutant huntingtin and the risk of neuronal death. Nature 431, 805-810 (2004).

Shows that inclusion body formation can be beneficial by sequestering toxic aggregates.

154 Liu, B. et al. The polarisome is required for segregation and retrograde transport of protein aggregates. Cell 140, 257-267, doi:10.1016/j.cell.2009.12.031 (2010).

Describes the machinery that controls the asymmetric distribution of aggregates during cell division in budding yeast. 
155 Hill, S. M., Hanzen, S. \& Nystrom, T. Restricted access: spatial sequestration of damaged proteins during stress and aging. EMBO Rep 18, 377391, doi:10.15252/embr.201643458 (2017).

156 Sontag, E. M., Samant, R. S. \& Frydman, J. Mechanisms and Functions of Spatial Protein Quality Control. Annual review of biochemistry 86, 97-122, doi:10.1146/annurev-biochem-060815-014616 (2017).

157 Ruan, L. et al. Cytosolic proteostasis through importing of misfolded proteins into mitochondria. Nature 543, 443-446, doi:10.1038/nature21695 (2017).

158 Rousseau, E. et al. Targeting expression of expanded polyglutamine proteins to the endoplasmic reticulum or mitochondria prevents their aggregation. Proc Natl Acad Sci U S A 101, 9648-9653, doi:10.1073/pnas.0403015101 (2004).

159 Vincenz-Donnelly, L. et al. High capacity of the endoplasmic reticulum to prevent secretion and aggregation of amyloidogenic proteins. The EMBO journal 37, 337-350, doi:10.15252/embj.201695841 (2018).

160 Rubinsztein, D. C., Marino, G. \& Kroemer, G. Autophagy and aging. Cell 146, 682-695, doi:10.1016/j.cell.2011.07.030 (2011).

161 Min, J. N. et al. CHIP deficiency decreases longevity, with accelerated aging phenotypes accompanied by altered protein quality control. Mol Cell Biol 28, 4018-4025, doi:10.1128/MCB.00296-08 (2008).

162 Labbadia, J. \& Morimoto, R. I. Repression of the Heat Shock Response Is a Programmed Event at the Onset of Reproduction. Mol Cell 59, 639-650, doi:10.1016/j.molcel.2015.06.027 (2015).

163 David, D. C. et al. Widespread protein aggregation as an inherent part of aging in C. elegans. PLoS biology 8, e1000450, doi:10.1371/journal.pbio.1000450 (2010).

164 Reis-Rodrigues, P. et al. Proteomic analysis of age-dependent changes in protein solubility identifies genes that modulate lifespan. Aging Cell 11, 120-127, doi:10.1111/j.1474-9726.2011.00765.x (2012).

165 Liang, V. et al. Altered proteostasis in aging and heat shock response in C. elegans revealed by analysis of the global and de novo synthesized proteome. Cell Mol Life Sci 71, 3339-3361, doi:10.1007/s00018-014-1558-7 (2014). 166 Walther, D. M. et al. Widespread Proteome Remodeling and Aggregation in Aging C. elegans. Cell 161, 919-932, doi:10.1016/j.cell.2015.03.032 (2015).

Analysis of proteome changes along the lifespan of $C$. elegans.

167 Zimmerman, S. M., Hinkson, I. V., Elias, J. E. \& Kim, S. K. Reproductive Aging Drives Protein Accumulation in the Uterus and Limits Lifespan in C. elegans. PLoS genetics 11, e1005725, doi:10.1371/journal.pgen.1005725 (2015).

168 Waldera-Lupa, D. M. et al. Proteome-wide analysis reveals an ageassociated cellular phenotype of in situ aged human fibroblasts. Aging (Albany NY) 6, 856-878, doi:10.18632/aging.100698 (2014).

169 Walther, D. M. \& Mann, M. Accurate quantification of more than 4000 mouse tissue proteins reveals minimal proteome changes during aging. Mol Cell Proteomics 10, M110 004523, doi:10.1074/mcp.M110.004523 (2011).

170 Ori, A. et al. Integrated Transcriptome and Proteome Analyses Reveal Organ-Specific Proteome Deterioration in Old Rats. Cell systems 1, 224-237, doi:10.1016/j.cels.2015.08.012 (2015). 
171 Ciryam, P., Kundra, R., Morimoto, R. I., Dobson, C. M. \& Vendruscolo, M. Supersaturation is a major driving force for protein aggregation in neurodegenerative diseases. Trends Pharmacol Sci 36, 72-77, doi:10.1016/j.tips.2014.12.004 (2015).

172 Ciryam, P., Tartaglia, G. G., Morimoto, R. I., Dobson, C. M. \& Vendruscolo, $\mathrm{M}$. Widespread aggregation and neurodegenerative diseases are associated with supersaturated proteins. Cell Rep 5, 781-790, doi:10.1016/j.celrep.2013.09.043 (2013).

Introduces supersaturation as a concept in controlling protein solubility. 173 Powers, E. T., Morimoto, R. I., Dillin, A., Kelly, J. W. \& Balch, W. E. Biological and chemical approaches to diseases of proteostasis deficiency. Annual review of biochemistry 78, 959-991, doi:10.1146/annurev.biochem.052308.114844 (2009).

174 Sala, A. J., Bott, L. C. \& Morimoto, R. I. Shaping proteostasis at the cellular, tissue, and organismal level. J Cell Biol 216, 1231-1241, doi:10.1083/jcb.201612111 (2017).

175 Brehme, M. et al. A chaperome subnetwork safeguards proteostasis in aging and neurodegenerative disease. Cell Rep 9, 1135-1150, doi:10.1016/j.celrep.2014.09.042 (2014).

Census of the human chaperome and description of a subnetwork that safeguards proteostasis.

176 Kitamura, A. et al. Dysregulation of the proteasome increases the toxicity of ALS-linked mutant SOD1. Genes to cells : devoted to molecular \& cellular mechanisms 19, 209-224, doi:10.1111/gtc.12125 (2014).

177 Gupta, R. et al. Firefly luciferase mutants as sensors of proteome stress. Nat Methods 8, 879-884, doi:10.1038/nmeth.1697 (2011).

178 Vilchez, D. et al. Increased proteasome activity in human embryonic stem cells is regulated by PSMD11. Nature 489, 304-308, doi:10.1038/nature11468 (2012).

Shows that stem cells have an increased level of proteasomal activity regulated by the proteasome subunit PSMD11.

179 Noormohammadi, A. et al. Somatic increase of CCT8 mimics proteostasis of human pluripotent stem cells and extends C. elegans lifespan. Nat Commun 7, 13649, doi:10.1038/ncomms13649 (2016).

180 Bufalino, M. R., DeVeale, B. \& van der Kooy, D. The asymmetric segregation of damaged proteins is stem cell-type dependent. J Cell Biol 201, 523-530, doi:10.1083/jcb.201207052 (2013).

181 Leeman, D. S. et al. Lysosome activation clears aggregates and enhances quiescent neural stem cell activation during aging. Science 359, 1277-1283, doi:10.1126/science.aag3048 (2018).

182 Moore, D. L., Pilz, G. A., Arauzo-Bravo, M. J., Barral, Y. \& Jessberger, S. A mechanism for the segregation of age in mammalian neural stem cells. Science 349, 1334-1338, doi:10.1126/science.aac9868 (2015).

183 Kenyon, C. The first long-lived mutants: discovery of the insulin/IGF-1 pathway for ageing. Philos Trans R Soc Lond B Biol Sci 366, 9-16, doi:10.1098/rstb.2010.0276 (2011).

184 Kenyon, C., Chang, J., Gensch, E., Rudner, A. \& Tabtiang, R. A C. elegans mutant that lives twice as long as wild type. Nature 366, 461-464, doi:10.1038/366461a0 (1993). 


\section{Shows that mutations in the daf-2 gene cause a dramatic lifespan extension in C. elegans.}

185 Kirstein-Miles, J., Scior, A., Deuerling, E. \& Morimoto, R. I. The nascent polypeptide-associated complex is a key regulator of proteostasis. The EMBO journal 32, 1451-1468, doi:10.1038/emboj.2013.87 (2013).

186 Stout, G. J. et al. Insulin/IGF-1-mediated longevity is marked by reduced protein metabolism. Molecular systems biology 9, 679, doi:10.1038/msb.2013.35 (2013).

187 Tsaytler, P., Harding, H. P., Ron, D. \& Bertolotti, A. Selective inhibition of a regulatory subunit of protein phosphatase 1 restores proteostasis. Science $\mathbf{3 3 2}$, 91-94, doi:10.1126/science.1201396 (2011).

188 Frakes, A. E. \& Dillin, A. The UPR(ER): Sensor and Coordinator of Organismal Homeostasis. Mol Cell 66, 761-771, doi:10.1016/j.molcel.2017.05.031 (2017).

189 Hansen, M. et al. Lifespan extension by conditions that inhibit translation in Caenorhabditis elegans. Aging Cell 6, 95-110, doi:10.1111/j.14749726.2006.00267.x (2007).

190 Pan, K. Z. et al. Inhibition of mRNA translation extends lifespan in Caenorhabditis elegans. Aging Cell 6, 111-119, doi:10.1111/j.14749726.2006.00266.x (2007).

191 Syntichaki, P., Troulinaki, K. \& Tavernarakis, N. eIF4E function in somatic cells modulates ageing in Caenorhabditis elegans. Nature 445, 922-926, doi:10.1038/nature05603 (2007).

192 Sherman, M. Y. \& Qian, S. B. Less is more: improving proteostasis by translation slow down. Trends in biochemical sciences 38, 585-591, doi:10.1016/j.tibs.2013.09.003 (2013).

193 Vilchez, D., Saez, I. \& Dillin, A. The role of protein clearance mechanisms in organismal ageing and age-related diseases. Nat Commun 5, 5659,

doi:10.1038/ncomms6659 (2014).

194 Caniard, A. et al. Proteasome function is not impaired in healthy aging of the lung. Aging (Albany NY) 7, 776-792, doi:10.18632/aging.100820 (2015). 195 Hamer, G., Matilainen, O. \& Holmberg, C. I. A photoconvertible reporter of the ubiquitin-proteasome system in vivo. Nat Methods 7, 473-478, doi:10.1038/nmeth.1460 (2010).

196 Tsakiri, E. N. et al. Differential regulation of proteasome functionality in reproductive vs. somatic tissues of Drosophila during aging or oxidative stress. FASEB J 27, 2407-2420, doi:10.1096/fj.12-221408 (2013).

197 Morrow, G. \& Tanguay, R. M. Drosophila melanogaster Hsp22: a mitochondrial small heat shock protein influencing the aging process. Frontiers in genetics 6, 1026, doi:10.3389/fgene.2015.00103 (2015).

198 Yamaguchi, T. et al. Age-related increase of insoluble, phosphorylated small heat shock proteins in human skeletal muscle. The journals of gerontology. Series A, Biological sciences and medical sciences 62, 481-489 (2007).

199 Jiao, W., Li, P., Zhang, J., Zhang, H. \& Chang, Z. Small heat-shock proteins function in the insoluble protein complex. Biochemical and biophysical research communications 335, 227-231, doi:10.1016/j.bbrc.2005.07.065 (2005).

200 Khan, S., Khamis, I. \& Heikkila, J. J. The small heat shock protein, HSP30, is associated with aggresome-like inclusion bodies in proteasomal inhibitor-, arsenite-, and cadmium-treated Xenopus kidney cells. Comparative biochemistry 
and physiology. Part A, Molecular \& integrative physiology 189, 130-140, doi:10.1016/j.cbpa.2015.07.022 (2015).

201 Walker, G. A. \& Lithgow, G. J. Lifespan extension in C. elegans by a molecular chaperone dependent upon insulin-like signals. Aging Cell 2, 131-139, doi:10.1046/j.1474-9728.2003.00045.x (2003).

202 Cohen, E., Bieschke, J., Perciavalle, R. M., Kelly, J. W. \& Dillin, A. Opposing activities protect against age-onset proteotoxicity. Science 313, 1604-1610, doi:10.1126/science.1124646 (2006).

Provides evidence for controlled protein aggregation during ageing as a beneficial process.

203 El-Ami, T. et al. A novel inhibitor of the insulin/IGF signaling pathway protects from age-onset, neurodegeneration-linked proteotoxicity. Aging Cell 13, 165-174, doi:10.1111/acel.12171 (2014).

204 Moll, L., Ben-Gedalya, T., Reuveni, H. \& Cohen, E. The inhibition of IGF-1 signaling promotes proteostasis by enhancing protein aggregation and deposition. FASEB J 30, 1656-1669, doi:10.1096/fj.15-281675 (2016). 205 Wild, E. J. \& Tabrizi, S. J. Therapies targeting DNA and RNA in Huntington's disease. Lancet Neurol 16, 837-847, doi:10.1016/S14744422(17)30280-6 (2017).

206 Cohen, F. E. \& Kelly, J. W. Therapeutic approaches to protein-misfolding diseases. Nature 426, 905-909, doi:10.1038/nature02265 (2003).

207 Sevigny, J. et al. The antibody aducanumab reduces Abeta plaques in Alzheimer's disease. Nature 537, 50-56, doi:10.1038/nature19323 (2016). 208 Bulawa, C. E. et al. Tafamidis, a potent and selective transthyretin kinetic stabilizer that inhibits the amyloid cascade. Proc Natl Acad Sci U S A 109, 96299634, doi:10.1073/pnas.1121005109 (2012).

Describes the first clinically effective anti-aggregation drug.

209 Baranczak, A. \& Kelly, J. W. A current pharmacologic agent versus the promise of next generation therapeutics to ameliorate protein misfolding and/or aggregation diseases. Curr Opin Chem Biol 32, 10-21, doi:10.1016/j.cbpa.2016.01.009 (2016).

210 Paxman, R. et al. Pharmacologic ATF6 activating compounds are metabolically activated to selectively modify endoplasmic reticulum proteins. Elife 7, doi:10.7554/eLife.37168 (2018).

211 Krobitsch, S. \& Lindquist, S. Aggregation of huntingtin in yeast varies with the length of the polyglutamine expansion and the expression of chaperone proteins. P Natl Acad Sci USA 97, 1589-1594 (2000).

212 Fonte, V. et al. Suppression of in vivo beta-amyloid peptide toxicity by overexpression of the HSP-16.2 small chaperone protein. J Biol Chem 283, 784791, doi:10.1074/jbc.M703339200 (2008).

213 Auluck, P. K., Chan, H. Y., Trojanowski, J. Q., Lee, V. M. \& Bonini, N. M. Chaperone suppression of alpha-synuclein toxicity in a Drosophila model for Parkinson's disease. Science 295, 865-868, doi:10.1126/science.1067389 (2002).

214 Warrick, J. M. et al. Suppression of polyglutamine-mediated neurodegeneration in Drosophila by the molecular chaperone HSP70. Nature genetics 23, 425-428, doi:10.1038/70532 (1999). 
215 Hoshino, T. et al. Suppression of Alzheimer's disease-related phenotypes by expression of heat shock protein 70 in mice. J Neurosci 31, 5225-5234, doi:10.1523/JNEUROSCI.5478-10.2011 (2011).

216 Cummings, C. J. et al. Over-expression of inducible HSP70 chaperone suppresses neuropathology and improves motor function in SCA1 mice. Human molecular genetics 10, 1511-1518 (2001).

217 Labbadia, J. et al. Suppression of protein aggregation by chaperone modification of high molecular weight complexes. Brain : a journal of neurology 135, 1180-1196, doi:10.1093/brain/aws022 (2012).

218 Sittler, A. et al. Geldanamycin activates a heat shock response and inhibits huntingtin aggregation in a cell culture model of Huntington's disease. Human molecular genetics 10, 1307-1315 (2001).

Shows that pharmacological induction of the stress response can prevent aggregation of a disease protein.

219 Nagy, M., Fenton, W. A., Li, D., Furtak, K. \& Horwich, A. L. Extended survival of misfolded G85R SOD1-linked ALS mice by transgenic expression of chaperone Hsp110. Proc Natl Acad Sci U S A 113, 5424-5428,

doi:10.1073/pnas.1604885113 (2016).

220 Calamini, B. et al. Small-molecule proteostasis regulators for protein conformational diseases. Nat Chem Biol 8, 185-196, doi:10.1038/nchembio.763 (2011).

221 Sontag, E. M. et al. Exogenous delivery of chaperonin subunit fragment ApiCCT1 modulates mutant Huntingtin cellular phenotypes. Proc Natl Acad Sci U $S$ A 110, 3077-3082, doi:10.1073/pnas.1222663110 (2013).

222 Das, I. et al. Preventing proteostasis diseases by selective inhibition of a phosphatase regulatory subunit. Science 348, 239-242, doi:10.1126/science.aaa4484 (2015).

223 Menzies, F. M. et al. Autophagy and Neurodegeneration: Pathogenic Mechanisms and Therapeutic Opportunities. Neuron 93, 1015-1034, doi:10.1016/j.neuron.2017.01.022 (2017).

224 Lee, B. H. et al. Enhancement of proteasome activity by a small-molecule inhibitor of USP14. Nature 467, 179-184, doi:10.1038/nature09299 (2010).

225 Rousseau, A. \& Bertolotti, A. An evolutionarily conserved pathway controls proteasome homeostasis. Nature 536, 184-189, doi:10.1038/nature18943 (2016).

Describes an evolutionarily conserved signalling pathway that controls proteasome homeostasis.

226 Mendillo, M. L. et al. HSF1 drives a transcriptional program distinct from heat shock to support highly malignant human cancers. Cell 150, 549-562, doi:10.1016/j.cell.2012.06.031 (2012).

227 Joshi, S. et al. Adapting to stress - chaperome networks in cancer. Nat Rev Cancer, doi:10.1038/s41568-018-0020-9 (2018).

228 Calderwood, S. K. \& Neckers, L. Hsp90 in Cancer: Transcriptional Roles in the Nucleus. Adv Cancer Res 129, 89-106, doi:10.1016/bs.acr.2015.08.002 (2016).

229 Joazeiro, C. A. P. Ribosomal Stalling During Translation: Providing Substrates for Ribosome-Associated Protein Quality Control. Annu Rev Cell Dev Biol 33, 343-368, doi:10.1146/annurev-cellbio-111315-125249 (2017). 
230 Bengtson, M. H. \& Joazeiro, C. A. Role of a ribosome-associated E3 ubiquitin ligase in protein quality control. Nature 467, 470-473, doi:10.1038/nature09371 (2010).

Identification of Listerin (Ltn1) as the E3 ligase critical for the protesomal degradation of failed nascent polypeptide chains on ribosomes.

231 Brandman, 0. et al. A ribosome-bound quality control complex triggers degradation of nascent peptides and signals translation stress. Cell 151, 10421054, doi:10.1016/j.cell.2012.10.044 (2012).

232 Shen, P. S. et al. Protein synthesis. Rqc2p and 60S ribosomal subunits mediate mRNA-independent elongation of nascent chains. Science 347, 75-78, doi:10.1126/science.1259724 (2015).

233 Kostova, K. K. et al. CAT-tailing as a fail-safe mechanism for efficient degradation of stalled nascent polypeptides. Science 357, 414-417, doi:10.1126/science.aam7787 (2017).

234 Defenouillere, Q. \& Fromont-Racine, M. The ribosome-bound quality control complex: from aberrant peptide clearance to proteostasis maintenance. Curr Genet 63, 997-1005, doi:10.1007/s00294-017-0708-5 (2017).

235 Izawa, T., Park, S. H., Zhao, L., Hartl, F. U. \& Neupert, W. Cytosolic Protein Vms1 Links Ribosome Quality Control to Mitochondrial and Cellular Homeostasis. Cell, doi:10.1016/j.cell.2017.10.002 (2017).

236 Nielson, J. R. et al. Sterol Oxidation Mediates Stress-Responsive Vms1 Translocation to Mitochondria. Mol Cell 68, 673-685 e676, doi:10.1016/j.molcel.2017.10.022 (2017).

237 Verma, R. et al. Vms1 and ANKZF1 peptidyl-tRNA hydrolases release nascent chains from stalled ribosomes. Nature, doi:10.1038/s41586-018-0022-5 (2018).

238 Zurita Rendon, 0. et al. Vms1p is a release factor for the ribosomeassociated quality control complex. Nat Commun 9, 2197, doi:10.1038/s41467018-04564-3 (2018).

239 Feng, J., Bussiere, F. \& Hekimi, S. Mitochondrial electron transport is a key determinant of life span in Caenorhabditis elegans. Dev Cell 1, 633-644 (2001). 240 Dillin, A. et al. Rates of behavior and aging specified by mitochondrial function during development. Science 298, 2398-2401, doi:10.1126/science.1077780 (2002).

241 Durieux, J., Wolff, S. \& Dillin, A. The cell-non-autonomous nature of electron transport chain-mediated longevity. Cell 144, 79-91, doi:10.1016/j.cell.2010.12.016 (2011).

242 Tian, Y. et al. Mitochondrial Stress Induces Chromatin Reorganization to Promote Longevity and UPR(mt). Cell 165, 1197-1208, doi:10.1016/j.cell.2016.04.011 (2016).

243 Merkwirth, C. et al. Two Conserved Histone Demethylases Regulate Mitochondrial Stress-Induced Longevity. Cell 165, 1209-1223, doi:10.1016/j.cell.2016.04.012 (2016).

244 Labbadia, J. et al. Mitochondrial Stress Restores the Heat Shock Response and Prevents Proteostasis Collapse during Aging. Cell Rep 21, 1481-1494, doi:10.1016/j.celrep.2017.10.038 (2017). 


\section{Box 1 |Ribosomal quality control}

Cells constantly produce faulty mRNA molecules, including truncated and prematurely polyadenylated forms that lack a stop codon (non-stop mRNA). Their translation results in aberrant nascent polypeptide chains that stall on the ribosome and must be degraded by a specialized ribosomal quality control machinery (RQC $)^{63,229}$. Ribosome stalling and RQC can also occur due to inhibitory mRNA stem-loop structures and suboptimal decoding of mRNA codons at the ribosome (nogo mRNAs). In the case of premature polyadenylation, translation of the polyA tail generates a C-terminal polylysine tract, which may aggravate stalling in the negatively charged ribosomal tunnel. In the yeast Saccharomyces cerevisiae, the RQC machinery comprises the E3 ubiquitin ligase Ltn1, the nucleotide-binding protein Rqc2 (NEMF in human), Rqc1 (TCF25 in human) and the AAA+ ATPase Cdc48 (VCP or P97 in human) and its cofactors ${ }^{230,231}$. The stalled ribosome is recognized by the ubiquitin ligase Hel2 (Znf598 in mammals) and splitting factors. Rqc2 binds the 60S subunit containing the stalled nascent chain and recruits Ltn1. Rqc2 elongates the stalled chain in a mRNA independent fashion by adding Ala and Thr residues to its Cterminus (so-called CAT-tails) ${ }^{232,233}$. Ltn1 ubiquitylates the stalled chain for recognition and extraction by Cdc48 (dependent on Rqc1), followed by proteasomal degradation. Deletion of Ltn1 causes stalled proteins to aggregate in a manner mediated by their CAT-tails ${ }^{64,65,234}$. In yeast cells these aggregates cause impairment of the proteostasis network by sequestering chaperone regulators, such as the Hsp40 Sis $1^{64,65}$. Mutation of Ltn1 causes neurodegeneration in a mouse model ${ }^{67}$.

$\mathrm{N}$-terminal signal sequences of stalled nascent chains can drive their import into mitochondria or ER. The cytosolic protein Vms1 is an additional RQC component protecting mitochondria against toxic effects of CAT-tail aggregates ${ }^{235}$. 
Vms1 binds to the outer mitochondrial membrane $(\mathrm{OM})^{236}$ and antagonizes the function of Rqc2 on $60 \mathrm{~S}$ ribosomes at the $\mathrm{OM}^{235}$ by acting as a peptidyl-tRNA hydrolase $\mathrm{e}^{237,238}$. As a result, stalled chains are released for import into the mitochondria before CAT-tails can be synthesized.

\section{Box 2 |Signalling pathways that modulate ageing and proteostasis}

Studies in model organisms showed that ageing and longevity are genetically regulated. Lifespan extension is achieved in three main ways: inhibition of the insulin/insulin-like growth factor 1 signalling (IIS) pathway, reduction of food intake, or attenuation of the mitochondrial electron transport chain (ETC).

\section{Insulin/insulin-like growth factor-1 signalling}

Identified in Caenorhabditis elegans as a lifespan-regulating signalling pathway ${ }^{183}$, IIS is conserved from worms to human and controls ageing, stress resistance and proteostasis by negatively regulating the nuclear translocation of transcription factors DAF-16 (FOXO; forkhead box O in mammals), HSF-1 (heat shock transcription factor-1) and SKN-1 (NRF-1; nuclear respiration factor 2 in mammals), which induce the expression of protective stress response pathways, such as the upregulation of chaperones and proteins protecting against oxidative damage (see Figure). Binding of insulin/insulin-like ligands to the DAF-2 receptor activates its tyrosine kinase activity and recruits AGE-1 (PI3K; phosphatidylinositol 3-kinase in mammals). This ultimately leads to phosphorylation of the downstream transcription factors, preventing their translocation into the nucleus. In contrast, reduced IIS in $d a f-2$ or age-1 mutant worms blocks this phosphorylation, allowing entry of DAF-16, HSF1 and SKN-1 into the nucleus for induction of genes required for extending lifespan and promoting stress resistance and enhancing proteostasis. 


\section{Dietary restriction}

Dietary restriction (i.e. reduced food intake without malnutrition) is the most robust intervention to increase lifespan and delay age-related dysfunction from yeast to mammals. In C. elegans, various cellular energy sensors such as AMPK (AMPactivated protein kinase) and TOR (target of rapamycin) mediate the beneficial effects of dietary restriction, supporting activation of PHA-4 (FOXOA in mammals), DAF16, HSF-1 and SKN-1. In addition, dietary restriction has been shown to induce autophagy.

\section{Mitochondrial electron transport chain}

Mutations affecting the mitochondrial ETC increase lifespan in C. elegans ${ }^{239-241}$. Such mutations cause (partial) uncoupling of the ETC and production of reactive oxygen species (ROS), which upregulates the mitochondrial unfolded protein response $\left(\mathrm{UPR}^{\mathrm{Mito}}\right)$. As long as ROS production is limited, this mechanism leads to a beneficial effect (hormesis). Details of the signalling pathways involved are just emerging: Mitochondrial stress causes chromatin remodeling in C. elegans, which is required for activation of UPR ${ }^{\text {Mito }}$ and stress-induced longevity. Two conserved histone lysine demethylases function as positive regulators of the ETC longevity pathway ${ }^{241-243}$. Recently it has been reported that mild mitochondrial stress is sufficient to maintain proteostasis, healthspan and stress resistance in an HSF1-dependent manner ${ }^{244}$, suggesting that the ETC is a central regulator of cytosolic proteostasis. 


\section{Figure legends:}

\section{Figure 1 |The proteostasis network prevents the formation of toxic aggregates}

(a) The proteostasis network contains all the factors that are necessary to control the functional levels of proteins in their native state and minimize non-productive or harmful off-pathway reactions (generation of unfolded proteins or aggregates; red). Proteostasis network components, which comprise approximately 2000 proteins in human cells, can be operationally assigned to three major arms: protein synthesis and folding (green), conformational maintenance (blue) and degradation (purple). In humans approximately 300 different molecular chaperones ${ }^{175}$ orchestrate these processes and function in folding, refolding and disaggregation reactions. They cooperate with the ubiquitin proteasome system and the autophagy-lysosomal machinery in the degradation of misfolded proteins and aggregates. (b) Proteins sample diverse conformations during folding, increasingly forming native intramolecular contacts as they progress downhill along a rugged energy landscape towards the thermodynamically stable, native state. Folding intermediates and misfolded states may accumulate as kinetically trapped species that need to traverse free energy barriers to form functional proteins. Intermolecular contacts between nonnative states may result in formation of various aggregates, oligomers, amorphous aggregates and amyloid fibrils, of which the latter may even be thermodynamically more stable than the native state. Molecular chaperones enhance on-pathway reactions that support progression of folding intermediates towards the native state and block off-pathway reactions that lead to misfolded and aggregated species. Various factors, such as mutations, stress, translation aberrations or defects in mRNA inhibit the onpathway reactions, favouring protein misfolding and aggregation. 


\section{Figure 2 | Mechanisms of aggregate toxicity}

(a) Oligomeric aggregates may form pores in cellular membranes ${ }^{105,106}$ (left panel), while fibrillar aggregates can interact with and deform membranes ${ }^{108,109}$ (right panel). (b) Chronic expression of aberrantly folded proteins caused by disease, ageing or external stress reduces proteostasis capacity by sequestering or otherwise inhibiting proteostasis network components, including (but not limited to) proteasomes ${ }^{126,127}$, chaperones ${ }^{119,120}$, nucleocytoplasmic transport factors ${ }^{111}$ and factors necessary to mount a successful stress response ${ }^{115,121}$. This will result in further misfolding and aggregation of endogenous proteins. These additional misfolded species in turn engage the proteostasis network, thereby further reducing available proteostasis capacity and driving a positive feedback loop that eventually leads to proteostasis collapse.

\section{Figure 3 | Mechanisms to counteract aggregate toxicity}

Cells employ various strategies to counteract the accumulation of toxic protein aggregates. Chaperones function to prevent aggregate formation, disassemble preexisting aggregates and facilitate the refolding of disaggregated proteins to the native state, or conformationally remodel toxic aggregates into less toxic or non-toxic forms. Notably, chaperone-mediated disaggregation of more complex aggregates such as amyloid fibres is linked to the generation of smaller oligomers, which are potentially more toxic than the larger aggregates. Thus, disassembly should be coupled to efficient degradation of abnormal protein species. Alternatively, the interactive surface area of the aggregate can be reduced by concentrating oligomeric species into large inclusions, which may contain fibrillar or amorphous aggregate material, or by shielding the aggregate surface with chaperones such as small heat 
shock proteins (sHSP). Aggregation-prone proteins can also be sequestered in subcellular locations, such as the nucleus or mitochondria, which show a higher tolerance for aggregation-prone proteins than the cytosol. In dividing cells it is also possible to retain the aggregated proteins in only one of the daughter cells through asymmetric cell division, thereby generating a rejuvenated daughter cell.

Figure 4 | Pro-longevity changes in the proteostasis network during ageing in $C$. elegans

(a) Schematics representing changes in abundance of cytosolic and mitochondrial ribosomes, molecular chaperones (small heat shock proteins (sHSP) and HSP70HSP90 system), oxidative defence machinery and proteasome complexes in wild-type and long-lived daf-2 mutant Caenorhabditis elegans worms as the animals age from day 1 of adulthood to day 22 (based on data from ref. ${ }^{166}$ ). Note that despite the increased abundance of the components of proteostasis networks, the activity of these mechanisms may nevertheless be insufficient to counteract the burden of misfolded proteins in aged wild-type animals. (b) Proteome protective activity of sHSP during ageing in wild-type and $d a f-2$ worms. Young adult worms maintain a balanced proteome by effectively clearing misfolded proteins. Ageing is associated with proteome imbalance, due to inefficient clearance of proteins, misregulated transcription and loss of the relative stoichiometries of protein complexes ${ }^{166}$. This results in supersaturation ${ }^{171,172}$ and aggregation of a subset of proteins and the accumulation of potentially toxic oligomer species. sHSP increase in abundance during ageing and have a protective role by sequestering soluble oligomers into insoluble inclusions and by shielding interactive aggregate surfaces. The stronger upregulation of sHSP in the daf-2 mutant allows for more effective sequestration of 
potentially dangerous aggregate material, maintaining proteome balance as the animals age.

Table 1: Main chaperone families and their functions in eukaryotes

\begin{tabular}{|c|c|}
\hline Molecular chaperone family & Function \\
\hline $\begin{array}{l}\text { HSP70 } \\
\sim 70 \mathrm{kDa} \\
\text { ATP-dependent }\end{array}$ & $\begin{array}{l}\text { Major chaperone family, comprising at least } \\
\text { eight homologous chaperone proteins located } \\
\text { in the cytoplasm, mitochondria and the ER. } \\
\text { These chaperones are required for } \\
\text { aggregation prevention, folding of newly- } \\
\text { synthesized proteins and for conformational } \\
\text { maintenance. They also cooperate with } \\
\text { HSP40 and HSP110 in protein } \\
\text { disaggregation. }\end{array}$ \\
\hline $\begin{array}{l}\text { HSP40 (also known as J proteins) } \\
\sim 40 \mathrm{kDa}\end{array}$ & $\begin{array}{l}\text { A diverse group of proteins, all containing the } \\
\text { HSP70-interacting J-domain, with } \\
\text { homologues in the cytoplasm, mitochondria } \\
\text { and the ER. They function as co-chaperones } \\
\text { of HSP70 and regulators of the HSP70 } \\
\text { ATPase cycle of protein substrate binding and } \\
\text { release. They recruit HSP70 to different } \\
\text { substrates and cellular locations. }\end{array}$ \\
\hline $\begin{array}{l}\text { HSP110 } \\
\sim 100 \mathrm{kDa}\end{array}$ & $\begin{array}{l}\text { Serves as a nucleotide exchange factor for } \\
\text { HSP70. Cooperates with HSP70 in protein } \\
\text { folding, degradation of misfolded proteins } \\
\text { and is critical for protein disaggregation in } \\
\text { metazoans. }\end{array}$ \\
\hline $\begin{array}{l}\text { HSP90 } \\
\sim 90 \mathrm{kDa} \\
\text { ATP-dependent }\end{array}$ & $\begin{array}{l}\text { Functions as a homodimer in the folding and } \\
\text { conformational regulation of functionally and } \\
\text { structurally diverse client proteins that are } \\
\text { involved in many different cellular pathways. } \\
\text { Major substrate classes are kinases, steroid } \\
\text { receptor molecules and other signaling } \\
\text { proteins. Cooperates with multiple co- } \\
\text { chaperones containing TPR (tetratricopeptide } \\
\text { repeat) domains. }\end{array}$ \\
\hline $\begin{array}{l}\text { HSP60 } \\
\sim 60 \text { kDa subunit } \\
\text { ATP-dependent }\end{array}$ & $\begin{array}{l}\text { The chaperonin of mitochondria. Consists of } \\
\text { two heptameric rings composed of } \sim 60 \mathrm{kDa} \\
\text { subunits, which are stacked back-to-back. } \\
\text { Cooperates with a cofactor, HSP } 10 \text {, and is } \\
\text { required for the folding of a subset of } \\
\text { mitochondrial proteins following their import } \\
\text { from the cytosol. }\end{array}$ \\
\hline $\begin{array}{l}\text { TRiC/CCT } \\
\sim 1 \mathrm{MDa}\end{array}$ & $\begin{array}{l}\text { The chaperonin of the eukaryotic cytosol. } \\
\text { Consists of two octameric rings composed of }\end{array}$ \\
\hline
\end{tabular}




\begin{tabular}{|l|l|}
\hline ATP-dependent & $\begin{array}{l}\sim 60 \mathrm{kDa} \text { subunits, which are stacked back-to- } \\
\text { back. Required for the folding of a subset of } \\
\text { cytosolic proteins, including actin and } \\
\text { tubulins. TRiC has also been shown to } \\
\text { interfere with the aggregation of Huntingtin. }\end{array}$ \\
\hline $\begin{array}{l}\text { Hsp100 } \\
\text { ATP-dependent }\end{array}$ & $\begin{array}{l}\text { A family of proteins in fungi, bacteria and } \\
\text { chloroplasts in plants (comprising Hsp104, } \\
\text { Hsp78, ClpA, ClpB, ClpC, ClpX and HsIU) } \\
\text { that belongs to a large superfamily of AAA+ } \\
\text { ATPases. These chaperones are typically } \\
\text { composed of hexameric rings. Hsp104 in } \\
\text { yeast and other fungi mediates protein } \\
\text { disaggregation in cooperation with Hsp70 and } \\
\text { Hsp40. }\end{array}$ \\
\hline Small HSP & $\begin{array}{l}\text { ATP-independent chaperones that form large } \\
\text { ( 1 MDa) heterogeneous oligomers. Subunits } \\
\text { contain a conserved } \alpha \text {-crystallin domain, } \\
\text { which is packed with } \beta \text {-sheets and involved in } \\
\text { oligomerization. 10 different forms in human } \\
\text { (HspB1-10). Prevent aggregation by binding } \\
\text { to non-native states ('holdase'-function) in } \\
\text { aggregation prevention but also mediate } \\
\text { sequestration of misfolded proteins into less } \\
\text { toxic aggregates. }\end{array}$ \\
\hline
\end{tabular}




\section{Glossary}

\section{Intrinsically disordered regions}

Regions of a protein that lack stable, well-defined tertiary structure; often functionally relevant in interactions with partner proteins.

\section{Tail-anchored proteins}

Membrane proteins that are post-translationally inserted into the membrane. They contain a transmembrane sequence near the carboxy-terminus.

\section{E3 ubiquitin ligase}

An enzyme that mediates the transfer of ubiquitin from an E2 ubiquitin-conjugating enzyme to a protein substrate.

\section{E2 ubiquitin-conjugating enzyme}

An enzyme that catalyzes the second step in the enzymatic cascade for the transfer of ubiquitin to protein substrates.

\section{Reticulocyte}

An immature red blood cell.

\section{Co-chaperone}

A factor that assists or regulates the function of a molecular chaperone; some cochaperones also have chaperone activity in binding non-native proteins.

\section{Chaperone-assisted selective autophagy}

Degradation pathway of chaperone-bound proteins in lysosomes.

\section{Chaperone-mediated autophagy}

Chaperone-dependent degradation pathway of soluble cytosolic proteins that involves translocation of the substrate protein across the lysosomal membrane.

\section{Endosomal microautophagy}

Degradation of cytosolic proteins by late endosomes/multivesicular bodies. 


\section{Amyloid}

A fibrillar aggregate, composed of polypeptides forming cross- $\beta$ structure that has defined tinctorial (dye-binding) properties.

\section{Low complexity domains}

Sequences of low amino acid diversity that are often intrinsically unstructured .

\section{Polyglutamine (polyQ) expansion}

Pathogenic elongation of a polyglutamine stretch in a protein caused by an increased number of CAG trinucleotide repeats; described in a group of unrelated genes.

\section{Chaperonin}

A class of molecular chaperones forming large, double-ring complexes that transiently enclose substrate protein for folding (examples include HSP60 in mitochondria and TRiC/CCT in the eukaryotic cytosol).

\section{BRICHOS domain}

A domain found in several proteins associated with dementia, respiratory distress and cancer, including BRI2, Chondromodulin-I and surfactant protein C. BRICHOS domains have intramolecular chaperone-like activities and inhibit misfolding and aggregation

\section{Critical concentration}

The concentration up to which a protein remains soluble; exceeding this concentration results in insolubility and aggregation.

\section{Unfolded protein response}

Cellular stress response pathways that serve to increase protein folding capacity of the endoplasmic reticulum $\left(\mathrm{UPR}^{\mathrm{ER}}\right)$ or the mitochondria (UPR $\left.{ }^{\mathrm{Mito}}\right)$.

\section{Integrated stress response}


A conserved signalling pathway that responds to a variety of cellular conditions and attenuates protein translation via phosphorylation of the translation initiation factor eIF $2 \alpha$.

\section{Transthyretin}

Tetrameric transport protein that binds the thyroid hormone thyroxin and retinolbinding protein. Mutant forms dissociate into subunits and aggregate, resulting in transthyretin amyloidosis.

\section{Hormesis}

An adaptive response of an organism or biological system towards a low dose of a toxic agent or physical conditions (e.g. reactive oxygen radicals or thermal stress) that preconditions the organism to tolerate a higher dose of the same toxic agent. 

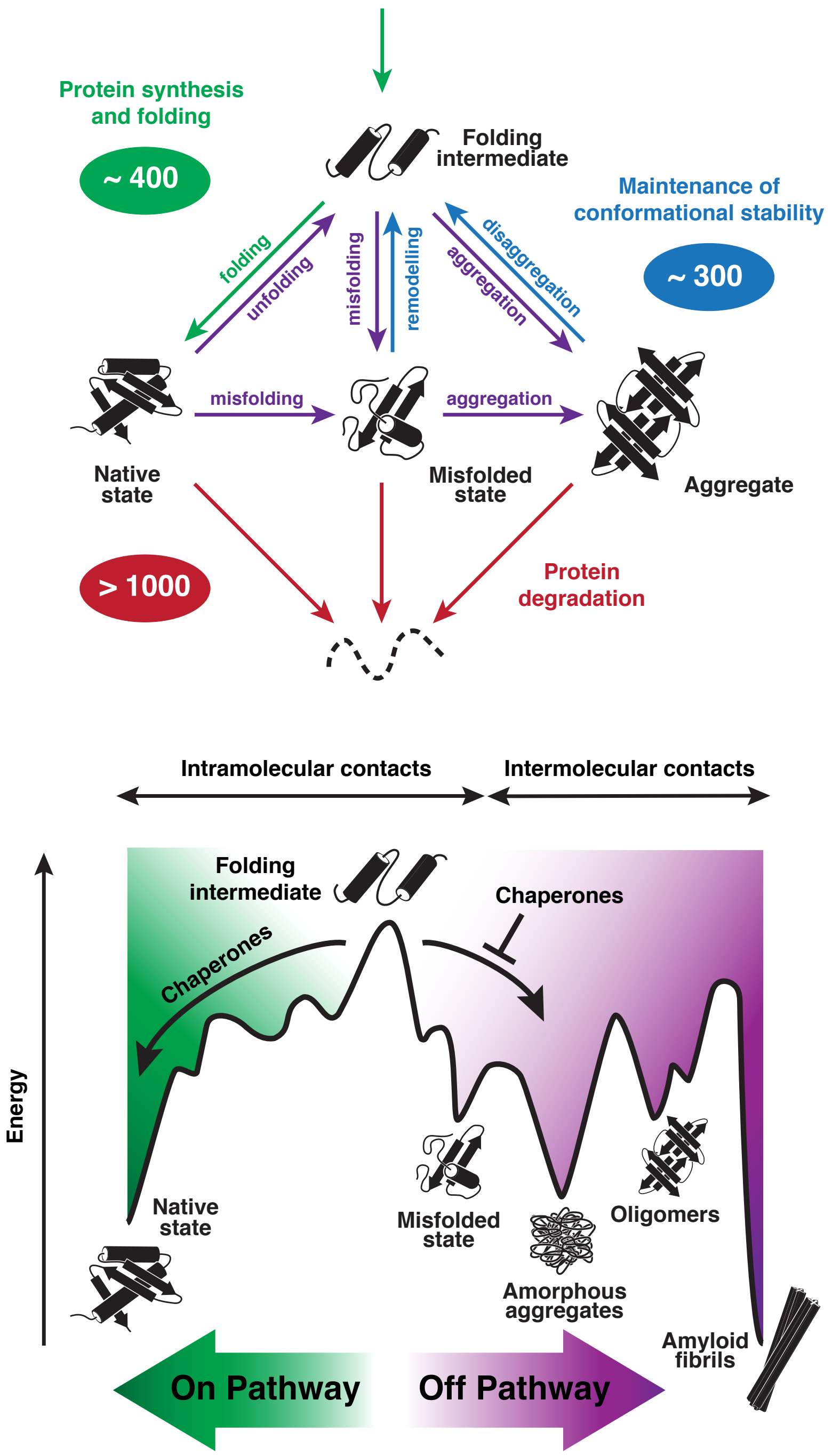
A

B
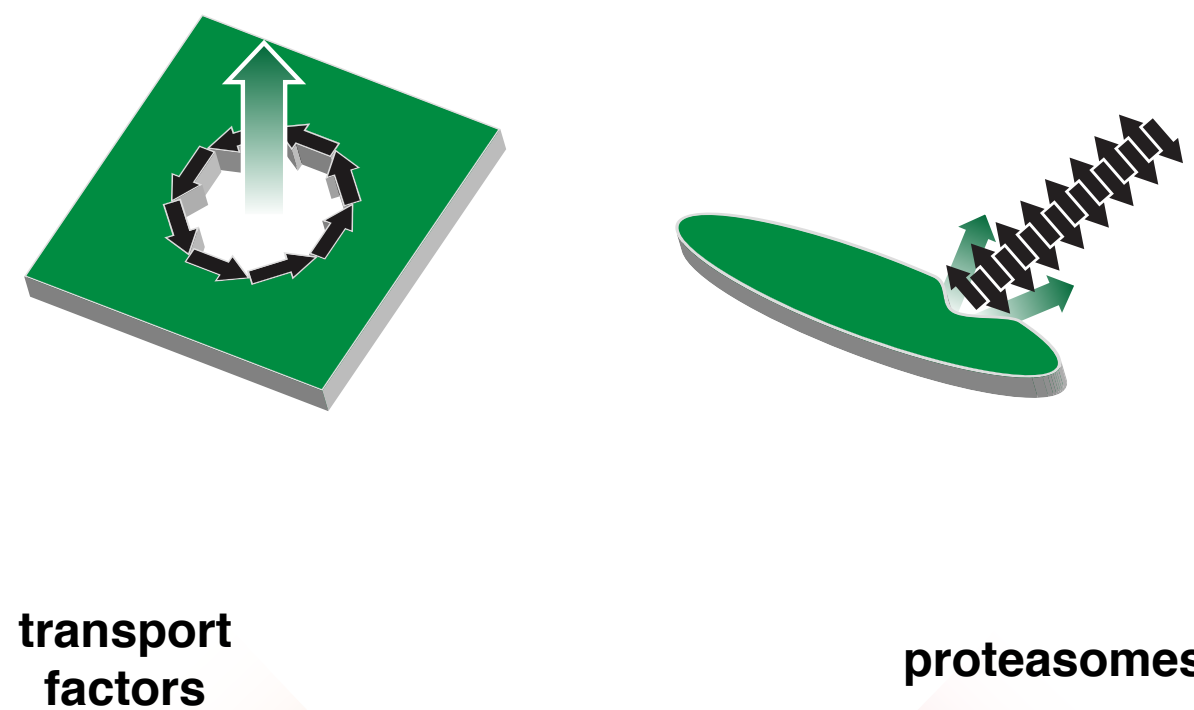

proteasomes
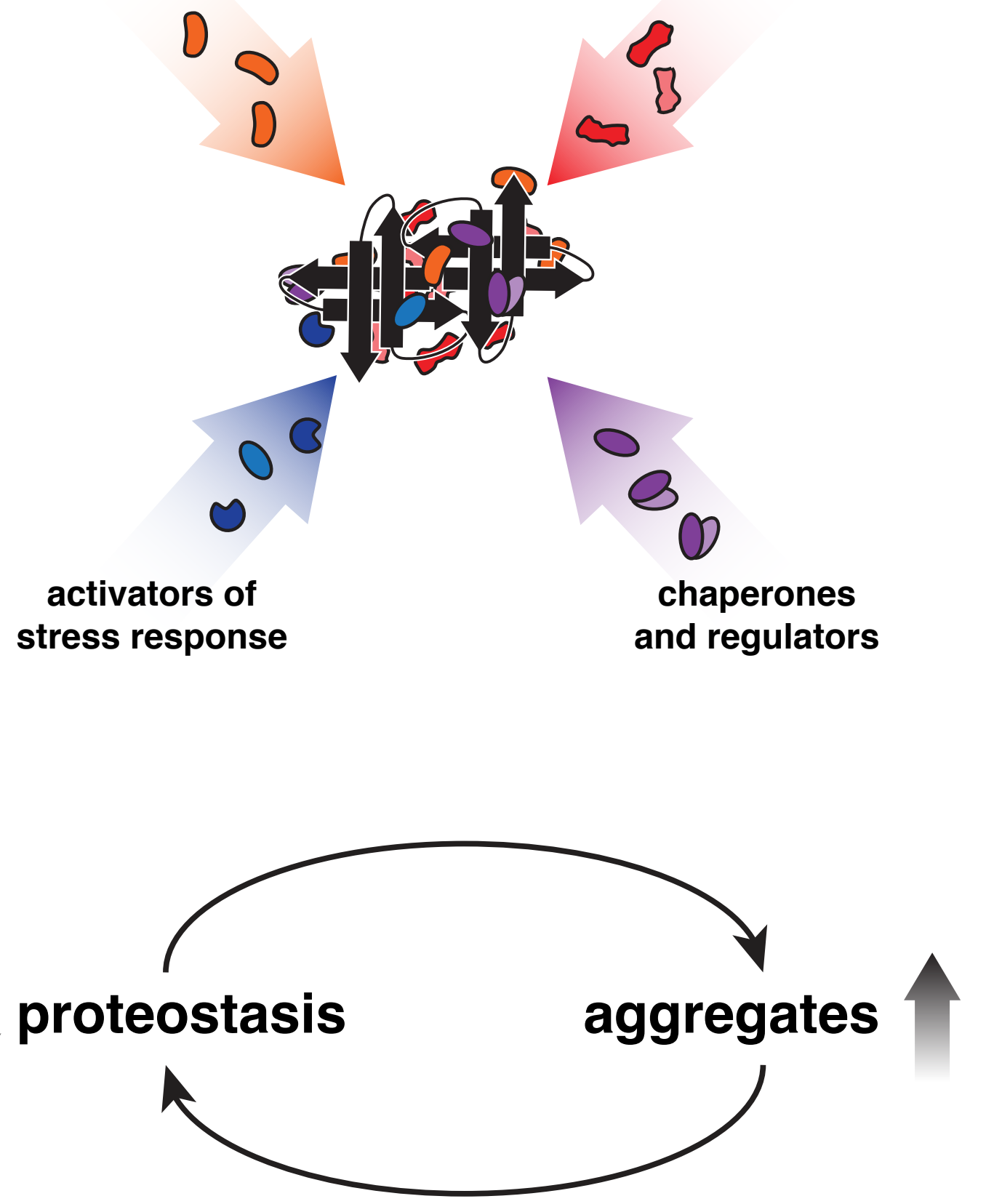


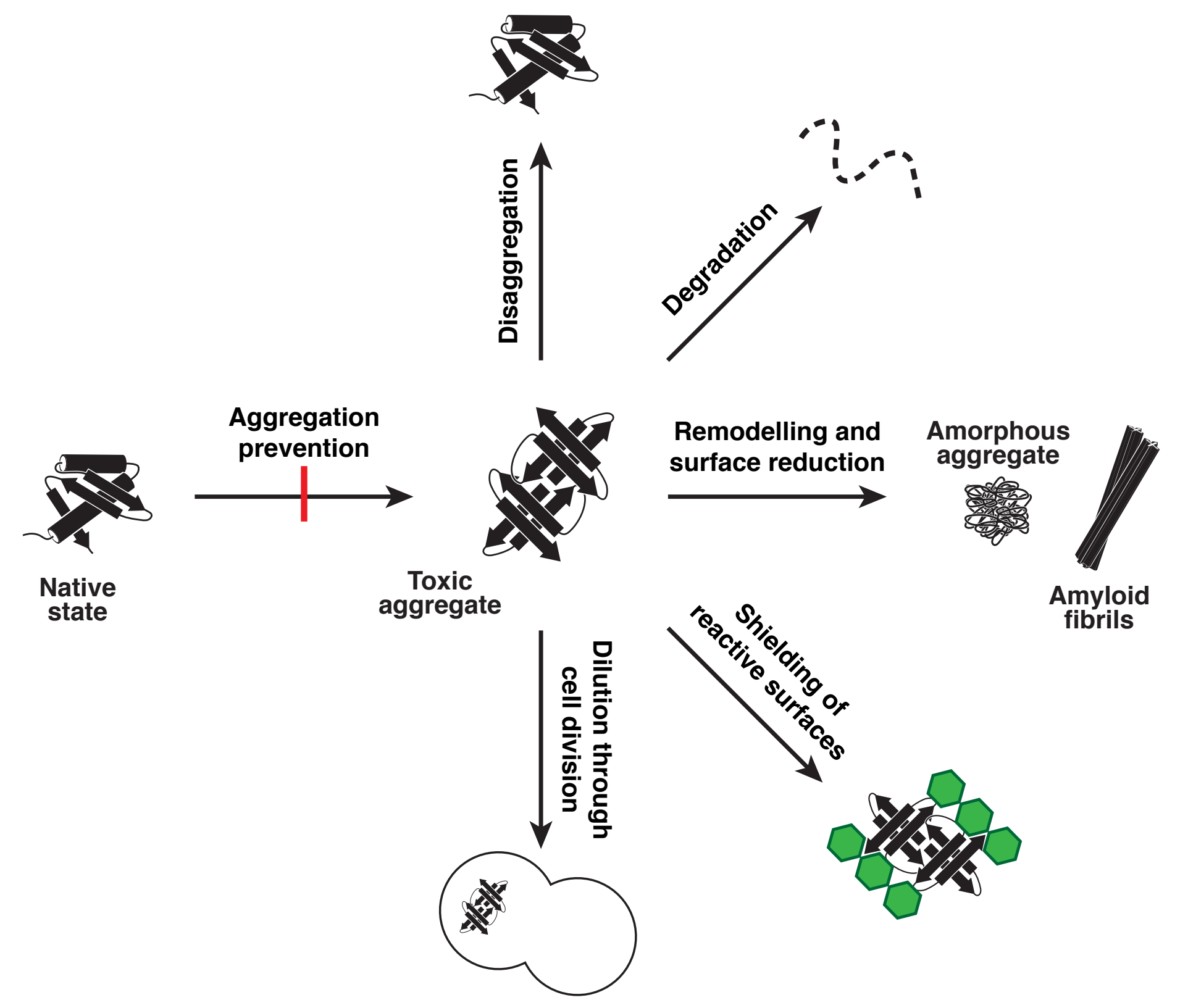


A

\section{Proteostasis network}
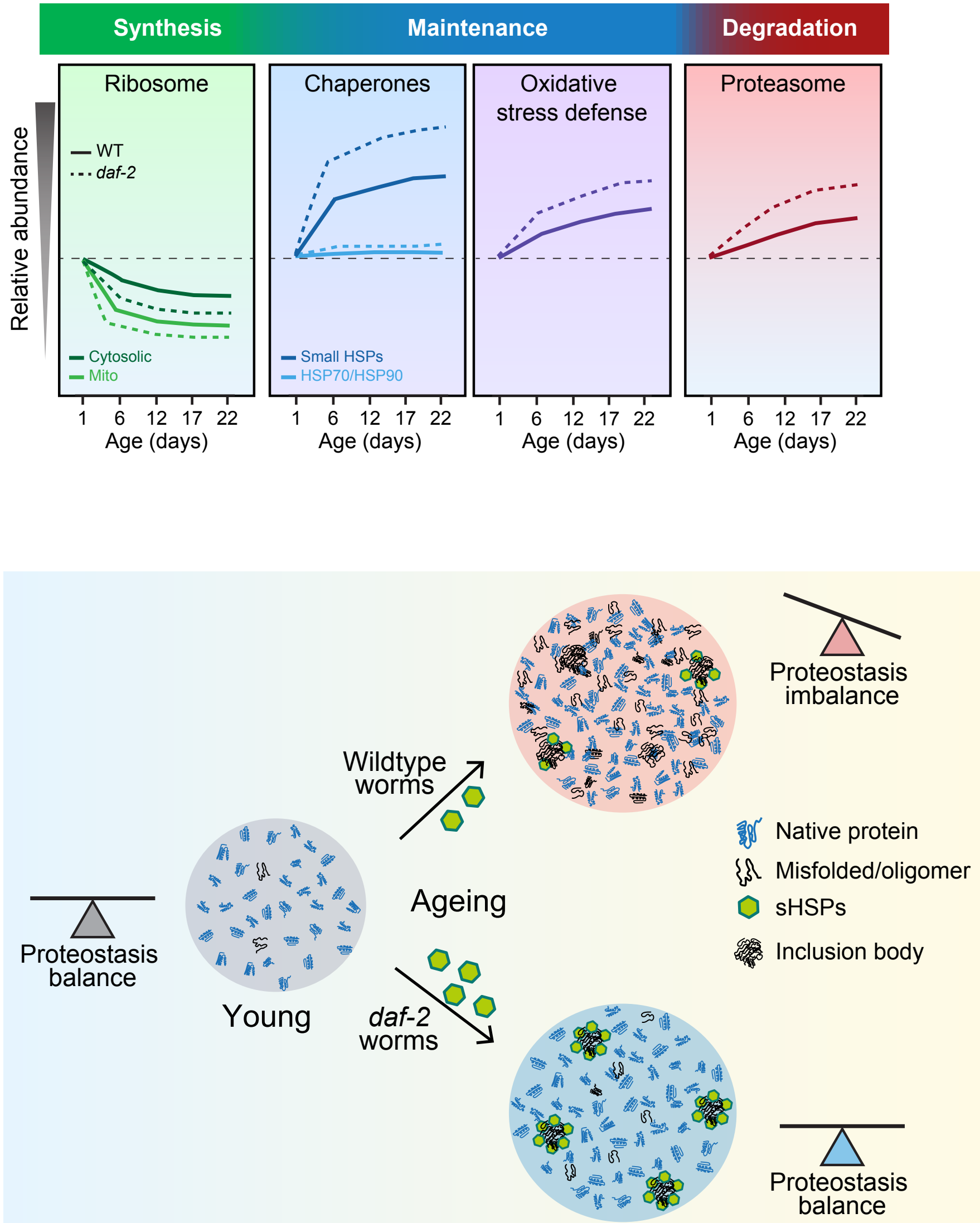


\section{Insulin/IGF1 receptor (DAF-2)}

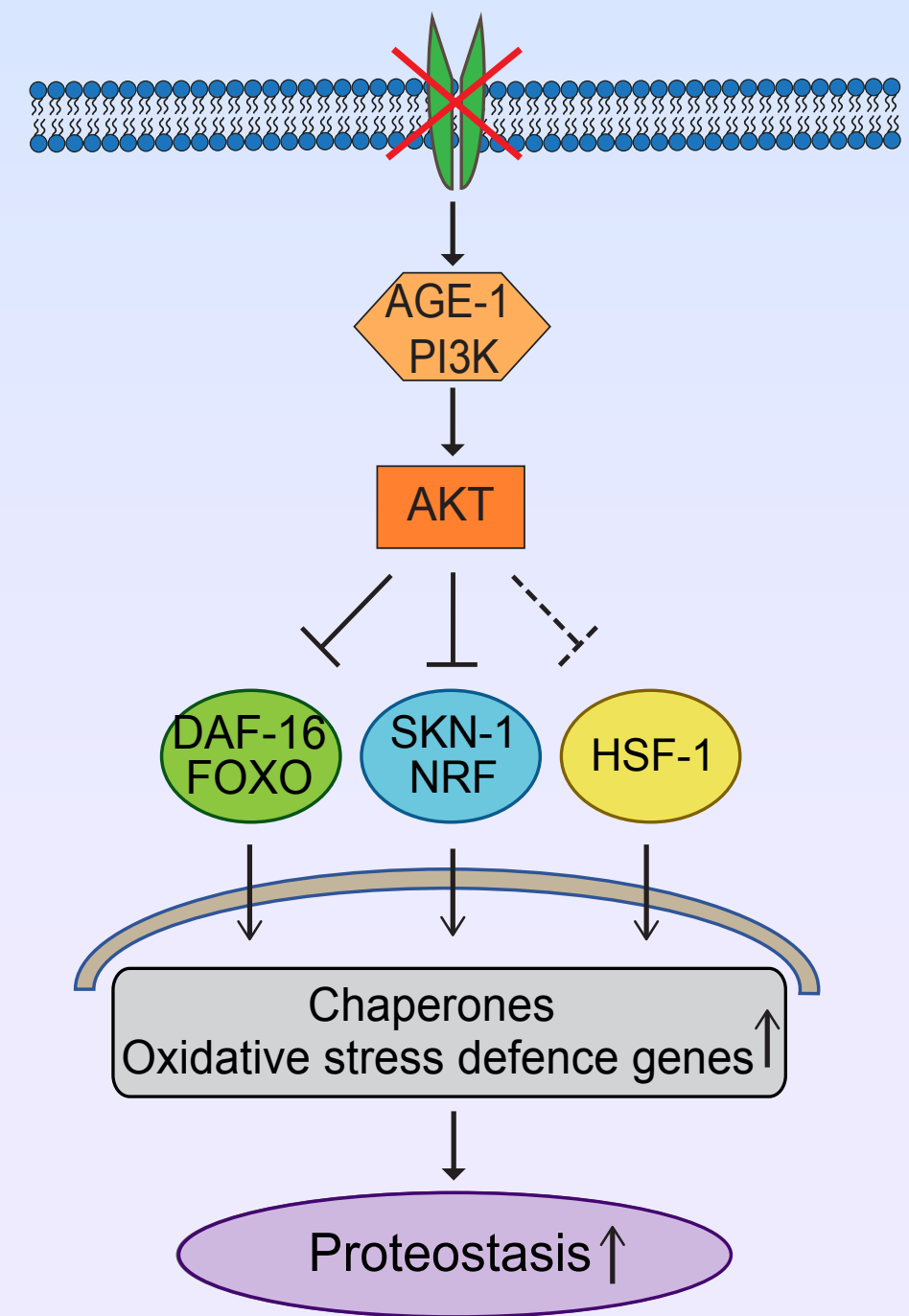

